\title{
FINANCIAL FIRM PRODUCTION OF INSIDE MONETARY AND CREDIT CARD SERVICES: AN
}

\section{AGGREGATION THEORETIC APPROACH ${ }^{1}$}

\author{
William A. Barnett \\ University of Kansas, Lawrence, and Center for Financial Stability, NY City \\ Liting Su \\ University of Kansas, Lawrence, and Center for Financial Stability, NY City
}

October 18, 2017

\begin{abstract}
A monetary-production model of financial firms is employed to investigate supply-side monetary aggregation, augmented to include credit card transaction services. Financial firms are conceived to produce monetary and credit card transaction services as outputs through financial intermediation. While credit cards provide transactions services, credit cards have never been included into measures of the money supply. The reason is accounting conventions, which do not permit adding liabilities to assets. However, index number theory measures service flows and is based on microeconomic aggregation theory, not accounting. Barnett, Chauvet, Leiva-Leon, and Su (2016) have derived and applied the relevant aggregation theory applicable to measuring the demand for the joint services of money and credit cards. But because of the existence of required reserves and differences in taxation on the demand and supply side, there is a regulatory wedge between the demand and supply of monetary services. We derive theory needed to measure the supply of the joint services of credit cards and money, to estimate the output supply function, and to compute value added. The resulting model can be used to investigate the transmission mechanism of monetary policy.

Earlier results on the monetary policy transmission mechanism based on the correlation between simple sum inside money and final targets are not likely to approximate or even be relevant to results that can be acquired by empirical implementation of this model or its extensions. Our financialfirm value-added measure and its supply function are fundamentally different from prior measures of inside money, shadow banking output, or money supply functions. The data needed for empirical implementation of our theory are available online from the Center for Financial Stability (CFS) in New York City. We show that the now discredited conventional accounting-based measures of privately produced inside money can be replaced by our measures, based on microeconomic aggregation theory, to provide the information originally contemplated in the literature on monetary theory for over a century.
\end{abstract}

\section{Introduction}

\footnotetext{
${ }^{1}$ We have benefitted from constructive comments provided by Kimberley Zieschang.
} 
Monetary policy is transmitted to the economy through banking firms and other financial intermediaries. Financial firms supply monetary assets through their financial intermediation between borrowers and lenders. The produced monetary assets play a central role in providing transaction services to the economy. In this context, rigorous microeconomic analysis of the optimal behavior of financial firms is essential to a clear understanding of the monetary transmission mechanism. We begin with the model of Barnett (1987) and generalize it to include production of credit card transactions services, using the approach developed initially for the demand side by Barnett, Chauvet, Leiva-Leon, and Su (2016).

The main objective of this study is to employ a production model of financial firms, which produce services through financial intermediation, and to investigate supply-side aggregation, when financial firms produce not only monetary services but also credit card transactions services. We derive the conditions under which a joint supply-side aggregate over monetary and credit card transactions services exists, and we produce the resulting formula permitting Divisia monetary aggregation over those joint services.

As the first step in this direction, we make many simplifying assumptions, the strongest of which is perfect certainty or risk neutrality. As a result, we are implicitly assuming the existence of complete contingent claims perfect markets, so that decentralization by owners to managers is incentive compatible, when owners are risk averse but managers are risk neutral. Generalizations under weaker assumptions are a subject for future research.

The ability to produce econometric models of financial intermediary production of transactions services could become a major source of future insights into the transmission mechanism of monetary policy. Since inside money produced by banking and shadow banking have become major factors affecting monetary policy, we consider the theory produced in this paper to be a first step in research we expect to grow in importance in future years. 
The theoretical foundation of the monetary production model is based on Barnett's (1987) monetary aggregation-theoretic approach, also consistent with Hancock's (1991) approach, but extended to include production of credit card transactions services. The role of produced credit card services has become far too important to overlook in modeling the output of financial firms and their contribution to transactions services in the economy. Financial firms are modeled as maximizing the discounted present value of variable profits, subject to given technology, while producing monetary assets and credit card services through financial intermediation. With the derivation of user-cost prices for monetary assets and credit card transaction services, the monetary production model can be transformed into the conventional neoclassical model of production by multiproduct firms. As a result, a neoclassical aggregate supply function on the production side can be constructed, using the existing literature on output aggregation.

The following section provides a general discussion of our model of the production of financial firms, based on Barnett's aggregation-theoretic approach, and describes the derivation of the user-cost prices for monetary assets and credit card services on the production side. The section also provides a discussion of aggregation theory relevant to our model formulation.

For a survey of the analogous results for monetary assets alone on the consumer demand side, see Barnett (2012). ${ }^{2}$ For the results augmented to include credit card services on the demand side, see Barnett, Chauvet, Leiva-Leon, and Su (2016). Those papers survey the available results on demand for monetary assets and exact aggregation over those demands along with the extension to inclusion of credit card transactions services. The current paper produces results dealing with the supply of monetary and credit card services produced by financial intermediaries and the aggregation over those supplies. We compute the relevant exact output aggregates, directly measuring inside money, in the

\footnotetext{
${ }^{2}$ Other relevant results on the demand side include Barnett and Chauvet (2011), Belongia and Ireland (2014), Barnett, Keating, and Kelly (2011), and Serletis and Gogas (2014).
} 
manner derived from out theory. Our resulting measures of inside money are now available from the Center for Financial Stability in New York City.

\section{The Model}

First, we define the variables that are used in the financial intermediary's decision problem:

$R_{t}=$ yield on the benchmark asset;

$\boldsymbol{\mu}_{\mathrm{t}}=$ real balances of monetary asset accounts serviced by the financial intermediary;

$\boldsymbol{\tau}_{t}=$ vector of real expenditures "volumes," $\tau_{j t}$, with credit card type $j$ for transactions during

period $t$

$\mathbf{e}_{t}=$ vector of expected interest rates, $e_{j t}$, on $\boldsymbol{\tau}_{t}$;

$\zeta_{t}=$ vector of rotating real balances, $\zeta_{j t}$, in credit card type $j$ during period $t$ from transactions

in previous periods;

$\overline{\mathbf{e}}_{t}=$ vector of interest rates on $\zeta_{t}$;

$C_{t}=$ real balances of excess reserves held by the intermediary during period $t$;

$\mathbf{L}_{t}=$ vector of labor quantities;

$\mathbf{z}_{t}=$ quantities of other factors of production;

$\mathbf{q}_{t}=$ prices of the factors, $\mathbf{z}_{t}$

$\mathbf{k}_{t}=$ reserve requirements, where $k_{i t}$ is the reserve requirement applicable to $\mu_{i t}$ and

$0 \leq k_{i t} \leq 1$ for all $i$

$R_{t}^{d}=$ Federal Reserve discount rate;

$\bar{R}_{t}=\min \left\{R_{t}, R_{t}^{d}\right\}$ 
$\boldsymbol{\rho}_{t}=$ vector of yields paid by the firm on $\boldsymbol{\mu}_{t}$.

The yield $R_{t}$ on the "benchmark asset" is the yield on an investment that provides no services other than the yield itself. In classical economic theory under general equilibrium, $R_{t}$ is "the interest rate" on pure capital and hence is secured by its ownership. In contrast, credit card loans are unsecured. The financial firm's efficient production technology is defined by the transformation function $F\left(\boldsymbol{\mu}_{t}, \boldsymbol{\tau}_{t}, \mathbf{z}_{t}, \mathbf{L}_{t}, c_{t} ; \mathbf{k}_{t}\right)=0$, assumed to be strictly quasiconvex in $\left(\boldsymbol{\mu}_{t}, \boldsymbol{\tau}_{t}, \mathbf{z}_{t}, \mathbf{L}_{t}, c_{t}\right)$, strictly increasing in outputs $\left(\boldsymbol{\mu}_{t}, \boldsymbol{\tau}_{t}\right)$ and strictly decreasing in inputs $\left(\mathbf{z}_{t}, \mathbf{L}_{t}, C_{t}\right)$. Since the intermediary's servicing of credit card transactions are during the current period, the firm's production technology includes $\tau_{t}$ but not $\zeta_{t}$. The value added in servicing transactions occurs during the period when the credit cards are used for transactions. ${ }^{3}$ Hence the firm's optimization decision is conditional upon consumer choices of $\zeta_{t}$, which convey no further services to consumers other than the unsecured rotating loan itself. The firm's technology can equivalently be defined by its efficient production set (production possibility set)

$$
S\left(\mathbf{k}_{t}\right)=\left\{\left(\boldsymbol{\mu}_{t}, \boldsymbol{\tau}_{t}, \mathbf{z}_{t}, \mathbf{L}_{t}, c_{t}\right) \geq \mathbf{0}: F\left(\boldsymbol{\mu}_{t}, \boldsymbol{\tau}_{t}, \mathbf{z}_{t}, \mathbf{L}_{t}, c_{t} ; \mathbf{k}_{t}\right)=0\right\}
$$

or by its production correspondence $F$, defined such that

$$
G\left(\mathbf{z}_{t}, \mathbf{L}_{t}, C_{t} ; \mathbf{k}_{t}\right)=\left\{\left(\boldsymbol{\mu}_{t}, \boldsymbol{\tau}_{t}\right) \geq \mathbf{0}:\left(\boldsymbol{\mu}_{t}, \boldsymbol{\tau}_{t}, \mathbf{z}_{t}, \mathbf{L}_{t}, c_{t}\right) \in S\left(\mathbf{k}_{t}\right)\right\}
$$

\footnotetext{
${ }^{3}$ The ability to borrow from lending institutions would exist, even if credit cards did not exist. Hence there is no value added in production from $\zeta_{t}$ in this model, for the same reason that the "benchmark" asset, having yield $R_{t}$, does not appear in the firm's technology. The value added from credit card servicing is the ability to buy goods with the card and defer payment. That service is provided th the time used to purchase the goods and is measured by credit card transactions "volumes," $\boldsymbol{\tau}_{t}$. To be able to impute value added to other financial intermediary lending, we would need to impute asset management services to the financial intermediary. The current model does not include asset management as a service of the financial intermediary. Results relevant to inclusion of asset management services can be found in Fixler and Zieschang $(2016 a, b)$.
} 
We assume that required reserves are never borrowed from the Federal Reserve, but could be borrowed in the federal funds market. ${ }^{4}$ Excess reserves can be borrowed from either source. In this initial model, we assume that the Federal Reserve does not pay interest on reserves, as has been the case during most of its history. The model could easily be modified to incorporate interest, as recently being paid on reserves. Since we are assuming the existence of only one kind of primary market loan yielding $R_{t}$, it follows that the federal funds rate must always equal $R_{t} \cdot{ }^{5}$ As a result, under our assumption of risk neutrality or perfect certainty, if $R_{t}^{d}<R_{t}$ then all excess reserves will be borrowed from the Federal Reserve and there are no free reserves. If $R_{t}^{d}>R_{t}$, then there is no borrowing from the Federal Reserve and free reserves equal excess reserves.

If $R_{t} \leq R_{t}^{d}$, then $\bar{R}_{t}=R_{t}$, and revenue from loans is

$$
\sum_{i}\left(\mu_{i t} p_{t}^{*}-\sum_{i} k_{i t} \mu_{i t} p_{t}^{*}-\sum_{j} p_{t}^{*} \tau_{j t}-\sum_{j} p_{t}^{*} \zeta_{j t}-c_{t} p_{t}^{*}-\mathbf{q}_{t}^{\prime} \mathbf{z}_{t}\right) R_{t}+\sum_{j} e_{j t} p_{t}^{*} \tau_{j t}+\sum_{j} \bar{e}_{j t} p_{t}^{*} \zeta_{j t}
$$

If $R_{t}>R_{t}^{d}$, then $\bar{R}_{t}=R_{t}^{d}$, and revenue from loans is

$$
\sum_{i}\left(\mu_{i t} p_{t}^{*}-\sum_{i} k_{i t} \mu_{i t} p_{t}^{*}-\sum_{j} p_{t}^{*} \tau_{j t}-\sum_{j} p_{t}^{*} \zeta_{j t}-\mathbf{q}_{t}^{\prime} \mathbf{z}_{t}\right) R_{t}-c_{t} p_{t}^{*} R_{t}^{d}+\sum_{j} e_{j t} p_{t}^{*} \tau_{j t}+\sum_{j} \bar{e}_{j t} p_{t}^{*} \zeta_{j t}
$$

Hence, in either case, revenue from loans is

$$
\left[\sum_{i}\left(1-k_{i t}\right) \mu_{i t} p_{t}^{*}-c_{t} p_{t}^{*}-\mathbf{q}_{t}^{\prime} \mathbf{z}_{t}-\sum_{j} p_{t}^{*} \tau_{j t}-\sum_{j} p_{t}^{*} \zeta_{j t}\right] R_{t}+c_{t} p_{t}^{*}\left(R_{t}-\bar{R}_{t}\right)+\sum_{j} e_{j t} p_{t}^{*} \tau_{j t}+\sum_{j} \bar{e}_{j t} p_{t}^{*} \zeta_{j t}
$$

\footnotetext{
4 This assumption of "perfect moral suasion" could easily be weakened or removed.

${ }^{5}$ Inclusion of multiple primary loan rates is a straightforward extension, which complicates the accounting and interpretation, without altering this paper's conclusions. We will use that extension, when we estimate financial firm technology in later research to implement the theory empirically.
} 
Variable cost, which must be paid out of revenue, is

$$
\sum_{i} \mu_{i t} p_{t}^{*} \rho_{i t}+\mathbf{q}_{t}^{\prime} \mathbf{z}_{t}+\mathbf{w}_{t}^{\prime} \mathbf{L}_{t}
$$

At the end of period $t$, profit received is acquired by subtracting (6) from (5). Dividing by $1+R_{t}$ to discount profits to the beginning of period $t$, we get the present value of period $t$ profits to be

$$
\begin{aligned}
& P\left(\boldsymbol{\mu}_{t}, \boldsymbol{\tau}_{t}, \zeta_{t}, \mathbf{z}_{t}, \mathbf{L}_{t}, c_{t} ; p_{t}^{*}, \mathbf{q}_{t}, R_{t}, R_{t}^{d}, \mathbf{e}_{t}, \overline{\mathbf{e}}_{t}, \boldsymbol{\rho}_{t}, \mathbf{w}_{t}, \mathbf{k}_{t}\right) \\
& =\boldsymbol{\mu}_{t}^{\prime} \boldsymbol{\gamma}_{t}+\boldsymbol{\tau}_{t}^{\prime} \tilde{\boldsymbol{\pi}}_{\mathbf{t}}+\zeta_{t}^{\prime} \boldsymbol{\sigma}_{t}-\mathbf{q}_{t}^{\prime} \mathbf{z}_{t}-\mathbf{L}_{t}^{\prime} \mathbf{w}_{t} /\left(1+R_{t}\right)-\gamma_{0 t} c_{t},
\end{aligned}
$$

where the vector $\gamma_{t}$ is defined such that the nominal user cost price for produced monetary asset $\mu_{i t}$ is $\gamma_{i t}=p_{t}^{*} \frac{\left(1-k_{i t}\right) R_{i t}-\rho_{i t}}{1+R_{t}}$. The vector $\tilde{\pi}_{\mathbf{t}}$ is defined such that the nominal user cost price for produced credit card services, $\tau_{j t}$, is

$$
\tilde{\pi}_{j t}=p_{t}^{*} \frac{e_{j t}-R_{t}}{1+R_{t}}
$$

the vector $\boldsymbol{\sigma}_{t}$ is defined such that the nominal user cost price for carried forward rotating credit card debt, $\zeta_{j t}$, is $\sigma_{j t}=p_{t}^{*} \frac{\bar{e}_{j t}-R_{t}}{1+R_{t}}$; and the nominal user cost price of excess reserves, $c_{t}$, is $\gamma_{o t}=p_{t}^{*} \frac{\bar{R}_{t}}{1+R_{t}}$. The corresponding real user costs are $\frac{\gamma_{t}}{p_{t}^{*}}, \frac{\tilde{\pi}_{t}}{p_{t}^{*}}, \frac{\sigma_{t}}{p_{t}^{*}}$, and $\frac{\gamma_{o t}}{p_{t}^{*}}$.

If we write the vector of all variable factor quantities as $\boldsymbol{\alpha}_{t}=\left(\mathbf{z}_{t}^{\prime}, \mathbf{L}_{t}^{\prime}, c_{t}\right)^{\prime}$ and the vector of corresponding factor prices as $\boldsymbol{\beta}_{t}=\left(\mathbf{q}_{t}^{\prime}, \mathbf{w}_{t}^{\prime} /\left(1+R_{t}\right), \gamma_{o t}\right)^{\prime}$, it becomes evident that profits take the conventional form $\boldsymbol{\mu}_{t}^{\prime} \boldsymbol{\gamma}_{t}+\boldsymbol{\tau}_{t}^{\prime} \tilde{\boldsymbol{\pi}}_{\mathbf{t}}+\zeta_{t}^{\prime} \boldsymbol{\sigma}_{t}-\boldsymbol{\alpha}_{t}^{\prime} \boldsymbol{\beta}_{t}$. But since the financial firm's decision is conditional upon consumer choice of $\zeta_{t}$, variable profits can be written as 


$$
P_{t}=\boldsymbol{\mu}_{t}^{\prime} \boldsymbol{\gamma}_{t}+\boldsymbol{\tau}_{t}^{\prime} \tilde{\boldsymbol{\pi}}_{\mathbf{t}}-\boldsymbol{\alpha}_{t}^{\prime} \boldsymbol{\beta}_{t}
$$

and the firm's variable profit maximization problem takes the conventional form of selecting

$\left(\boldsymbol{\mu}_{t}, \boldsymbol{\tau}_{t}, \mathbf{z}_{t}, \mathbf{L}_{t}, C_{t}\right) \in S\left(\mathbf{k}_{t}\right)$ to maximize (8). Hence the existing literature on output aggregation for multiproduct firms becomes immediately applicable to aggregation over the produced monetary services $\left(\boldsymbol{\mu}_{t}, \boldsymbol{\tau}_{t}\right)$ and to measuring value added and technological change in financial intermediation.

Observe that the technology, $F$, is aggregated over firms. When our model's outputs consist of credit card services and components of the Federal Reserve's narrow monetary aggregates, the aggregated financial firm could be considered to be aggregate bank technology. But when the outputs of the firm include components of the broader aggregates, M3 and M4, the technology is aggregated over other relevant financial firms along with banks, since some of the components of M3 and M4 are produced by shadow banking. In fact even M2 contains a shadow banking output: money market funds. ${ }^{6}$

\section{Properties of the Model}

Following Barnett (1987), variable revenue from deposits can be written in the form

$$
\boldsymbol{\mu}_{t}^{\prime} \boldsymbol{\gamma}_{t}=\boldsymbol{\mu}_{t}^{\prime} \boldsymbol{\pi}_{t}^{s}-\frac{p_{t}^{*} R_{t} \mathbf{k}_{t}^{\prime} \boldsymbol{\mu}_{t}}{1+R_{t}}
$$

where

$$
\pi_{i t}^{s}=p_{t}^{*} \frac{R_{t}-\rho_{i t}}{1+R_{t}}
$$

\footnotetext{
${ }^{6}$ It should be acknowledged that the problems of aggregating over firms without the assumption of perfect competition are challenging. See, e.g., Sato (1975). In this initial paper, we are assuming perfect certainty. But as mentioned below, future extensions of this work to take account of credit rationing might require weakening that assumption. Such extensions are likely to introduce distribution effects into the aggregate technology.
} 
has the same form as the demand-side monetary-asset user-cost formula derived by Barnett

$(1978,1980)$ for consumers. Clearly $\pi_{i t}^{s}$ in (10) would equal $\gamma_{i t}$ if $\mathbf{k}_{t}=0$, removing the regulatory

wedge between the demand and supply side. ${ }^{7}$ For credit card transaction services, $\tilde{\pi}_{j t}$ equals exactly

the demand-side user cost of credit card services derived by Barnett, Chauvet, Leiva-Leon, and Su (2016)

for consumers, since there is no regulatory wedge between the demand and supply side for credit card services.

The solution to the firm's variable profit-maximization problem is its factor demand functions

for $\boldsymbol{\alpha}=\left(\mathbf{z}_{t}^{\prime}, \mathbf{L}_{t}^{\prime}, C_{t}\right)^{\prime}$ and the supply functions for its multiple products $\left(\boldsymbol{\mu}_{t}, \boldsymbol{\tau}_{t}\right)$ conditionally upon

consumers' choices of $\zeta_{t}$. Derived demand is thereby produced for high-powered (base) money. That

derived demand, in real terms, is

$$
h_{t}=c_{t}+\sum_{i} k_{i t} \mu_{i t}
$$

The financial firm's nominal demand for high-powered money is $p_{t}^{*} h_{t}$.

\section{Separability of Technology}

Following Barnett (1987), we assume there exist functions $f$ and $H$ such that

$$
F\left(\boldsymbol{\mu}_{t}, \boldsymbol{\tau}_{t}, \mathbf{z}_{t}, \mathbf{L}_{t}, c_{t} ; \mathbf{k}_{t}\right)=H\left(f\left(\boldsymbol{\mu}_{t}, \boldsymbol{\tau}_{t} ; \mathbf{k}_{t}\right), \mathbf{z}_{t}, \mathbf{L}_{t}, c_{t}\right){ }^{8}
$$

\footnotetext{
${ }^{7}$ There also is a regulatory wedge caused be differences in taxation on the demand and supply side. That wedge is not explicitly considered in this paper.

${ }^{8}$ The resulting functional structure is called blockwise weak separability. A large literature exists on testing weakly separable function structure, such as Cherchye, Demuynck, Rock, and Hjerstrand (2015) and Hjertstrand, Swofford, and Whitney (2016). Parametric tests requiring specification of the firm's technology could be based on the generalized Barnett model used by Barnett and Hahm (1994) or generalized McFadden (quadratic) models used in Barnett and Zhou (1994) and Barnett, Kirova, and Pasupathy (1995). While those studies did not include credit card services, the same econometric methodologies could be used to test for blockwise weak separability of the outputs, including produced credit card services.
} 
Under the usual neoclassical assumptions on technology, there will exist a function $g$ such that

$$
f\left(\boldsymbol{\mu}_{t}, \boldsymbol{\tau}_{t} ; \mathbf{k}_{t}\right)=g\left(\mathbf{z}_{t}, \mathbf{L}_{t}, c_{t}\right)
$$

is the solution for $f\left(\boldsymbol{\mu}_{t}, \boldsymbol{\tau}_{t} ; \mathbf{k}_{t}\right)$ to

$$
H\left(f\left(\boldsymbol{\mu}_{t}, \boldsymbol{\tau}_{t} ; \mathbf{k}_{t}\right), \mathbf{z}_{t}, \mathbf{L}_{t}, c_{t}\right)=0
$$

The function $f\left(\boldsymbol{\mu}_{t}, \boldsymbol{\tau}_{t} ; \mathbf{k}_{t}\right)$ is called the factor requirements function, because it equals the right-hand side of (13), which is the minimum amount of aggregate input required to produce the vector $\left(\boldsymbol{\mu}_{t}, \boldsymbol{\tau}_{t}\right)$. The function $g\left(\mathbf{z}_{t}, \mathbf{L}_{t}, c_{t}\right)$ is the production function, because it equals the left-hand side of (13), which is the maximum amount of aggregate output that can be produced from the inputs $\left(\mathbf{z}_{t}, \mathbf{L}_{\mathbf{t}}, C_{t}\right)$. Hence $f$ is both the factor requirements function and the outputs aggregator function, $M_{t}^{s}=f\left(\boldsymbol{\mu}_{t}, \boldsymbol{\tau}_{t} ; \mathbf{k}_{t}\right)$, while $g$ is both the output production function and the inputs aggregator function.

We assume that $f$ is convex and linearly homogeneous in $\boldsymbol{\mu}_{\mathbf{t}}$ and $\boldsymbol{\tau}_{t}$. In addition, it follows from our assumptions on the neoclassical properties of the transformation function $F$, that $g$ is monotonically increasing in all of its arguments and that $f$ is monotonically increasing in $\boldsymbol{\mu}_{\mathbf{t}}$ and $\boldsymbol{\tau}_{t}$. We assume that $g$ is locally strictly concave in a neighborhood of the solution to the first-order conditions for variable profit maximization. In addition, it follows, from the strict quasiconvexity of the transformation function $F$, that $g$ is globally strictly quasiconcave.

\section{Financial Intermediary Aggregation Theory Under Homogeneity}

In this section, we produce a two-stage decision for the financial intermediary. In the first stage, the firm solves for profit-maximizing factor demands and the profit-maximizing level of aggregate 
financial services produced. In the second stage, the revenue-maximizing vector of individual financial service quantities supplied is determined at fixed aggregate financial service quantity supplied.

To display that decomposition of the firm's profit-maximization decision, we start by defining the relevant revenue functions. The financial firm's revenue function is

$$
W\left(\boldsymbol{\alpha}_{t}, \boldsymbol{\gamma}_{\mathbf{t}}, \tilde{\boldsymbol{\pi}}_{t}, \boldsymbol{\sigma}_{t}, \zeta_{t} ; \mathbf{k}_{\mathbf{t}}\right)=\max _{\left\{\boldsymbol{\mu}_{\mathbf{t}}, \boldsymbol{\tau}_{t}\right\}}\left\{\boldsymbol{\mu}_{t}^{\prime} \boldsymbol{\gamma}_{t}+\boldsymbol{\tau}_{t}^{\prime} \tilde{\boldsymbol{\pi}}_{\mathbf{t}}+\boldsymbol{\zeta}_{t}^{\prime} \boldsymbol{\sigma}_{t}: f\left(\boldsymbol{\mu}_{t}, \boldsymbol{\tau}_{t} ; \mathbf{k}_{t}\right)=g\left(\boldsymbol{\alpha}_{t}\right)\right\}
$$

Since the decision is conditional on consumer choice of $\zeta_{t}$, the financial firm's variable revenue function can be written as

$$
R^{*}\left(\boldsymbol{\alpha}_{t}, \boldsymbol{\gamma}_{\mathbf{t}}, \tilde{\boldsymbol{\pi}}_{t} ; \mathbf{k}_{\mathbf{t}}\right)=\max _{\left\{\boldsymbol{\mu}_{\mathbf{t}}, \boldsymbol{\tau}_{t}\right\}}\left\{\boldsymbol{\mu}_{t}^{\prime} \boldsymbol{\gamma}_{t}+\boldsymbol{\tau}_{t}^{\prime} \tilde{\boldsymbol{\pi}}_{\mathbf{t}}: f\left(\boldsymbol{\mu}_{t}, \boldsymbol{\tau}_{t} ; \mathbf{k}_{t}\right)=g\left(\boldsymbol{\alpha}_{t}\right)\right\}
$$

where the firm selects $\boldsymbol{\alpha}_{t}$ to maximize variable profits

$$
P_{t}=R^{*}\left(\boldsymbol{\alpha}_{t}, \boldsymbol{\gamma}_{t}, \tilde{\boldsymbol{\pi}}_{t} ; \mathbf{k}_{t}\right)-\boldsymbol{\alpha}_{t}^{\prime} \boldsymbol{\beta}_{t}
$$

However, by Shephard's (1970, p. 251) Proposition 83, it follows that there exists a linearly homogeneous output price aggregator function $\Gamma$ such that

$$
R^{*}\left(\boldsymbol{\alpha}_{t}, \boldsymbol{\gamma}_{t}, \tilde{\boldsymbol{\pi}}_{t} ; \mathbf{k}_{t}\right)=\Gamma\left(\boldsymbol{\gamma}_{t}, \tilde{\boldsymbol{\pi}}_{t}\right) g\left(\boldsymbol{\alpha}_{t}\right)
$$

Hence the financial firm's variable profits can alternatively be written as

$$
P_{t}=\Gamma\left(\boldsymbol{\gamma}_{t}, \tilde{\boldsymbol{\pi}}_{t}\right) g\left(\boldsymbol{\alpha}_{\mathbf{t}}\right)-\boldsymbol{\alpha}_{t}^{\prime} \boldsymbol{\beta}_{t}
$$

The firm's first-stage decision is to select $\boldsymbol{\alpha}_{t}^{*}$ to maximize (18). Substituting the optimized input vector $\boldsymbol{\alpha}_{t}^{*}$ into $g\left(\boldsymbol{\alpha}_{t}\right)$, the firm can compute the optimum aggregate financial service quantity supplied, $M_{t}^{s}$, including both monetary services and credit card transaction services supplied. In stage two of the 
decentralized decision, $M_{t}^{s}$ is substituted into (15) to replace $g\left(\boldsymbol{\alpha}_{t}\right)$, and the maximization problem in (15) is solved to acquire the optimum vector of supplied monetary assets $\boldsymbol{\mu}_{t}$ and credit card transaction volumes $\tau_{t}$, conditionally upon consumer's choices of carried-forward credit card debt, $\zeta_{t}$. Observe that the intermediary's supply function for its output aggregate is produced from stage one alone.

Clearly, the exact economic output quantity aggregate for the financial firm is

$$
M_{t}^{s}=f\left(\boldsymbol{\mu}_{t}^{*}, \boldsymbol{\tau}_{t}^{*} ; \mathbf{k}_{t}\right)
$$

when $\left(\boldsymbol{\mu}_{t}^{*}, \boldsymbol{\tau}_{t}^{*}\right)$ is the variable profit-maximizing vector of monetary assets and credit card transaction volumes produced. The corresponding variable output price aggregate is

$$
\Gamma_{t}^{s}=\Gamma\left(\gamma_{t}, \tilde{\boldsymbol{\pi}}_{t}\right)
$$

Fisher's output reversal test states that $M_{t}^{s} \Gamma_{t}^{s}$ must equal actual revenue from production of $\left(\boldsymbol{\mu}_{\mathbf{t}}^{*}, \boldsymbol{\tau}_{t}^{*}\right)$. That condition is satisfied as a result of (15) and (17), and the fact that $f\left(\boldsymbol{\mu}_{t}^{*}, \boldsymbol{\tau}_{t}^{*} ; \mathbf{k}_{\mathbf{t}}\right)$ must equal $g\left(\boldsymbol{\alpha}_{t}\right)$ at $\boldsymbol{\alpha}_{\mathbf{t}}=\boldsymbol{\alpha}_{\mathbf{t}}^{*}$. Also observe from (15) and (17), with $g\left(\boldsymbol{\alpha}_{t}\right)$ set equal to 1.0, that the variable output price aggregate is equal to

$$
\Gamma\left(\boldsymbol{\gamma}_{t}, \tilde{\boldsymbol{\pi}}_{t}\right)=\max _{\left\{\boldsymbol{\mu}_{t}, \boldsymbol{\tau}_{t}\right\}}\left\{\boldsymbol{\mu}_{t}^{\prime} \boldsymbol{\gamma}_{t}+\boldsymbol{\tau}_{t}^{\prime} \tilde{\boldsymbol{\pi}}_{\mathbf{t}}: f\left(\boldsymbol{\mu}_{t}, \boldsymbol{\tau}_{t} ; \mathbf{k}_{\mathbf{t}}\right)=1\right\}
$$

which is the unit variable revenue function. The unit variable revenue function is the maximum variable revenue that can be acquired from the production of one unit of the output monetary aggregate, $M_{t}^{s}=f\left(\boldsymbol{\mu}_{t}, \boldsymbol{\tau}_{t} ; \mathbf{k}_{\mathbf{t}}\right)$. The linear homogeneity of $\Gamma$ is clear from (21). In addition, the unit revenue function is convex and increasing in $\left(\boldsymbol{\gamma}_{t}, \tilde{\pi}_{t}\right)$ and increasing in $\left(\boldsymbol{\sigma}_{t}, \zeta_{t}\right)$.

Instead of maximizing $\boldsymbol{\mu}_{t}^{\prime} \boldsymbol{\gamma}_{t}+\boldsymbol{\tau}_{t}^{\prime} \tilde{\boldsymbol{\pi}}_{\mathbf{t}}$ subject to 


$$
f\left(\boldsymbol{\mu}_{t}, \boldsymbol{\tau}_{t} ; \mathbf{k}_{t}\right)=g\left(\boldsymbol{\alpha}_{t}^{*}\right)
$$

to acquire the stage-two solution for $\left(\boldsymbol{\mu}_{\mathrm{t}}^{*}, \boldsymbol{\tau}_{t}^{*}\right)$ conditionally upon consumer choices of $\zeta_{t}^{*}$, we could equivalently define the stage-two decision to be the selection of $\left(\boldsymbol{\mu}_{\mathbf{t}}^{*}, \boldsymbol{\tau}_{t}^{*}\right)$ to minimize the aggregate factor requirement $f\left(\boldsymbol{\mu}_{t}, \boldsymbol{\tau}_{t} ; \mathbf{k}_{t}\right)$ subject to

$$
\boldsymbol{\mu}_{t}^{\prime} \boldsymbol{\gamma}_{t}+\boldsymbol{\tau}_{t}^{\prime} \tilde{\boldsymbol{\pi}}_{\mathbf{t}}=\Gamma\left(\boldsymbol{\gamma}_{t}, \tilde{\boldsymbol{\pi}}_{t}\right) g\left(\boldsymbol{\alpha}_{t}^{*}\right)
$$

As a result, we can rewrite (19) to obtain

$$
M_{t}^{s}=\min _{\left\{\boldsymbol{\mu}_{t}, \boldsymbol{\tau}_{t}\right\}}\left\{f\left(\boldsymbol{\mu}_{t}, \boldsymbol{\tau}_{t} ; \mathbf{k}_{t}\right): \boldsymbol{\mu}_{t}^{\prime} \boldsymbol{\gamma}_{t}+\boldsymbol{\tau}_{t}^{\prime} \tilde{\boldsymbol{\pi}}_{\mathbf{t}}=\Gamma\left(\boldsymbol{\gamma}_{t}, \tilde{\boldsymbol{\pi}}_{t}\right) g\left(\boldsymbol{\alpha}_{t}^{*}\right)\right\}
$$

while our earlier statement of the stage-two decision produces the equivalent result that

$$
M_{t}^{s} \Gamma\left(\boldsymbol{\gamma}_{t}, \tilde{\boldsymbol{\pi}}_{t}\right)=\max _{\left\{\boldsymbol{\mu}_{t}, \boldsymbol{\tau}_{t}\right\}}\left\{\boldsymbol{\mu}_{t}^{\prime} \boldsymbol{\gamma}_{t}+\boldsymbol{\tau}_{t}^{\prime} \tilde{\boldsymbol{\pi}}_{\mathbf{t}}: f\left(\boldsymbol{\mu}_{t}, \boldsymbol{\tau}_{t} ; \mathbf{k}_{\mathbf{t}}\right)=g\left(\boldsymbol{\alpha}_{t}^{*}\right)\right\}
$$

Comparing (21) and (22), we can see the clear duality between the decision problems. As usual, the exact quantity and price aggregates of economic theory are true duals.

Equation (21) defines the unit revenue (output price aggregator) function in terms of the factor requirement (output quantity aggregator) function. The converse is also possible as a result of the fact that

$$
f\left(\boldsymbol{\mu}_{t}^{*}, \boldsymbol{\tau}_{t}^{*} ; \mathbf{k}_{\mathbf{t}}\right)=\left[\min _{\gamma_{t} \geq \mathbf{0}}\left\{\Gamma\left(\boldsymbol{\gamma}_{t}, \tilde{\boldsymbol{\pi}}_{t}\right): \boldsymbol{\mu}_{t}^{* \prime} \boldsymbol{\gamma}_{t}+\boldsymbol{\tau}_{t}^{* \prime} \tilde{\boldsymbol{\pi}}_{t}=1\right\}\right]^{-1},
$$

using equation (3.2) in Diewert (1976).

\section{Financial Intermediary Index Number Theory Under Homogeneity}


Monetary output aggregation is produced by solving the financial intermediary's second-stage decision for $\left(\boldsymbol{\mu}_{t}^{* \prime}, \boldsymbol{\tau}_{t}^{* \prime}\right)^{\prime}$ and substituting it into $f$ to acquire $M_{t}^{s}=f\left(\boldsymbol{\mu}_{t}^{*}, \boldsymbol{\tau}_{t}^{*} ; \mathbf{k}_{t}\right)$. That second-stage decision is to select $\left(\boldsymbol{\mu}_{t}^{* \prime}, \boldsymbol{\tau}_{t}^{* \prime}\right)^{\prime}$ to

$$
\max \boldsymbol{\mu}_{t}^{\prime} \boldsymbol{\gamma}_{t}+\boldsymbol{\tau}_{t}^{\prime} \tilde{\boldsymbol{\pi}}_{\mathbf{t}}+\zeta_{t}^{\prime} \boldsymbol{\sigma}_{t} \quad \text { subject to } f\left(\boldsymbol{\mu}_{t}, \boldsymbol{\tau}_{t} ; \mathbf{k}_{\mathbf{t}}\right)=M_{t}^{s}
$$

But since the decision is conditional on consumer choice of $\zeta_{t}$, the decision is equivalent to selecting $\left(\boldsymbol{\mu}_{t}^{* \prime}, \boldsymbol{\tau}_{t}^{* \prime}\right)^{\prime}$ to maximize variable revenue as follows:

$$
\max \boldsymbol{\mu}_{t}^{\prime} \boldsymbol{\gamma}_{t}+\boldsymbol{\tau}_{t}^{\prime} \tilde{\boldsymbol{\pi}}_{\mathbf{t}} \quad \text { subject to } f\left(\boldsymbol{\mu}_{t}, \boldsymbol{\tau}_{t} ; \mathbf{k}_{\mathbf{t}}\right)=M_{t}^{s}
$$

The following theorem proves that the Divisia index tracks $M_{t}^{s}$ without error in continuous time, so long as $\left(\boldsymbol{\mu}_{t}^{* \prime}, \boldsymbol{\tau}_{t}^{*^{\prime}}\right)^{\prime}$ is continually selected to solve (24b) at each instant, $t$.

Theorem 1. If $\left(\boldsymbol{\mu}_{t}^{* \prime}, \boldsymbol{\tau}_{t}^{* \prime}\right)^{\prime}$ solves (24b) continually at each instant $t \in T_{0}$, then for every $t \in T_{0}$

$$
d \log M_{t}^{s} / d t=\sum_{i} s_{i t} d \log \mu_{i t}^{*} / d t+\sum_{j} u_{j t} d \log \tau_{j t}^{*} / d t
$$

where $s_{i t}=\mu_{i t}^{*} \gamma_{i t} /\left(\boldsymbol{\mu}_{t}^{* \prime} \boldsymbol{\gamma}_{t}+\boldsymbol{\tau}_{t}^{* \prime} \tilde{\boldsymbol{\pi}}_{t}\right)$ and $u_{j t}=\tau_{j t}^{*} \tilde{\pi}_{j t} /\left(\boldsymbol{\mu}_{t}^{* \prime} \boldsymbol{\gamma}_{t}+\boldsymbol{\tau}_{t}^{* \prime} \tilde{\boldsymbol{\pi}}_{t}\right)$.

Proof: The first-order conditions for solution to (24b) are

$$
\begin{aligned}
& \gamma_{i t}=-\lambda \partial f / \partial \mu_{i t}, \\
& \tilde{\pi}_{j t}=-\lambda \partial f / \partial \tau_{j t},
\end{aligned}
$$

and $f\left(\boldsymbol{\mu}_{t}^{*}, \boldsymbol{\tau}_{\mathbf{t}}^{*} ; \mathbf{k}_{\mathbf{t}}^{*}\right)=M_{t}^{s}$, where $\lambda$ are the Lagrange multipliers.

Compute the total differential of $f$ to acquire 


$$
d f\left(\boldsymbol{\mu}_{\mathbf{t}}, \boldsymbol{\tau}_{\mathbf{t}} ; \mathbf{k}_{\mathbf{t}}\right)=\sum_{i} \frac{\partial f}{\partial \mu_{i t}} d \mu_{i t}+\sum_{j} \frac{\partial f}{\partial \tau_{j t}} d \tau_{j t} .
$$

Substitute (26) and (27) to find, at $\boldsymbol{\mu}_{t}=\boldsymbol{\mu}_{t}^{*}$ and $\boldsymbol{\tau}_{t}=\boldsymbol{\tau}_{t}^{*}$, that

$$
d f\left(\boldsymbol{\mu}_{t}^{*}, \boldsymbol{\tau}_{t}^{*} ; \mathbf{k}_{t}\right)=-\frac{1}{\lambda} \sum_{i} \gamma_{i t} d \mu_{i t}^{*}-\frac{1}{\lambda} \sum_{j} \tilde{\pi}_{j t} d \tau_{j t}^{*} .
$$

But by summing (26) over $i$ and (27) over $j$, solving for $\lambda$, and substituting into (28), we obtain

$$
\begin{aligned}
d \log f\left(\boldsymbol{\mu}_{t}^{*}, \boldsymbol{\tau}_{t}^{*} ; \mathbf{k}_{t}\right)= & \frac{\boldsymbol{\mu}_{t}^{* \prime} \partial f / \partial \boldsymbol{\mu}_{t}+\boldsymbol{\tau}_{t}^{* \prime} \partial f / \partial \boldsymbol{\tau}_{t}}{f\left(\boldsymbol{\mu}_{t}^{*}, \boldsymbol{\tau}_{t}^{*} ; \mathbf{k}_{t}\right)} \sum_{i} \frac{\mu_{i t}^{*} \gamma_{i t}}{\boldsymbol{\mu}_{t}^{* \prime} \boldsymbol{\gamma}_{t}+\boldsymbol{\tau}_{t}^{* \prime} \tilde{\boldsymbol{\pi}}_{t}} d \log \mu_{i t}^{*} \\
& +\frac{\boldsymbol{\mu}_{t}^{* \prime} \partial f / \partial \boldsymbol{\mu}_{t}+\boldsymbol{\tau}_{t}^{* \prime} \partial f / \partial \boldsymbol{\tau}_{t}}{f\left(\boldsymbol{\mu}_{t}^{*}, \boldsymbol{\tau}_{t}^{*} ; \mathbf{k}_{t}\right)} \sum_{j} \frac{\tau_{j t}^{*} \tilde{\pi}_{j t}}{\boldsymbol{\mu}_{t}^{* \prime} \boldsymbol{\gamma}_{t}+\boldsymbol{\tau}_{t}^{* \prime} \tilde{\boldsymbol{\pi}}_{t}} d \log \tau_{i t}^{*} .
\end{aligned}
$$

Since $f$ is linearly homogeneous in $\boldsymbol{\mu}_{\mathbf{t}}$ and $\boldsymbol{\tau}_{t}$, we have from Euler's equation that

$$
\boldsymbol{\mu}_{t}^{* \prime} \partial f / \partial \boldsymbol{\mu}_{t}+\boldsymbol{\tau}_{t}^{* \prime} \partial f / \partial \boldsymbol{\tau}_{t}=f\left(\boldsymbol{\mu}_{t}^{*}, \boldsymbol{\tau}_{t}^{*} ; \mathbf{k}_{\mathbf{t}}\right)
$$

Substituting (30) into (29), we obtain

$$
d \log f\left(\boldsymbol{\mu}_{t}^{*}, \boldsymbol{\tau}_{t}^{*} ; \mathbf{k}_{t}\right) / d t=\sum_{i} s_{i t} d \log \mu_{i t}^{*} / d t+\sum_{j} u_{j t} d \log \tau_{j t}^{*} / d t
$$

where $s_{i t}=\mu_{i t}^{*} \gamma_{i t} /\left(\boldsymbol{\mu}_{t}^{* \prime} \gamma_{t}+\boldsymbol{\tau}_{t}^{* \prime} \tilde{\boldsymbol{\pi}}_{t}\right)$ and $u_{j t}=\tau_{j t}^{*} \tilde{\pi}_{j t} /\left(\boldsymbol{\mu}_{t}^{* \prime} \boldsymbol{\gamma}_{t}+\boldsymbol{\tau}_{t}^{* \prime} \tilde{\boldsymbol{\pi}}_{t}\right)$

Hence the Divisia index is equally as applicable to aggregating over the monetary services and credit card transaction services produced by the financial intermediary as over the monetary services and credit card transactions services by the consumers, as derived by Barnett, Chauvet, Leiva-Leon, and Su (2016). In addition, Simpson's rule produces the Törnqvist-Theil discrete time approximation

$$
\log M_{t}^{s}-\log M_{t-1}^{s}=\sum_{i} \bar{s}_{i t}\left(\log \mu_{i t}^{*}-\log \mu_{i, t-1}^{*}\right)+\sum_{j} \bar{u}_{j t}\left(\log \tau_{j t}^{*}-\log \tau_{j, t-1}^{*}\right)
$$


where $\bar{s}_{i t}=\frac{1}{2}\left(s_{i t}+s_{i, t-1}\right)$ and $\bar{u}_{j t}=\frac{1}{2}\left(u_{j t}+u_{j, t-1}\right)$. Furthermore, if the input requirement function $f$ is translog, then the discrete Divisia index (32) is exact in discrete time [see Diewert (1976, p. 125)]. Hence (32) is a superlative index number.

Having produced the output quantity aggregate from the Divisia index, the dual price aggregate is produced from variable output reversal,

$$
\Gamma_{t}=\left(\boldsymbol{\mu}_{t}^{* \prime} \boldsymbol{\gamma}_{t}+\boldsymbol{\tau}_{t}^{* \prime} \tilde{\boldsymbol{\pi}}_{t}\right) / M_{t}^{s}
$$

The user-cost price index produced in that manner is called the implicit Divisia price index. The resulting price index is superlative in the Diewert sense, as is easily shown from (33) and the fact that $M_{t}^{s}$ is superlative.

\section{Financial Intermediary Aggregation Without Homotheticity}

Define the financial firm's output distance function implicitly to be the value of $D\left(\boldsymbol{\mu}_{t}, \boldsymbol{\tau}_{t}, \boldsymbol{\alpha}_{t} ; \mathbf{k}_{t}\right)$ that solves

$$
f\left(\left(\boldsymbol{\mu}_{t}, \boldsymbol{\tau}_{\mathbf{t}}\right) / D\left(\boldsymbol{\mu}_{t}, \boldsymbol{\tau}_{t}, \boldsymbol{\alpha}_{t} ; \mathbf{k}_{t}\right) ; \mathbf{k}_{\mathbf{t}}\right)=g\left(\boldsymbol{\alpha}_{0}\right)
$$

for preselected reference input vector $\boldsymbol{\alpha}_{0}$. Then the exact monetary quantity output aggregate for the financial intermediary is

$$
M^{s}\left(\boldsymbol{\mu}_{t}, \boldsymbol{\tau}_{t} ; \boldsymbol{\alpha}_{0}, \mathbf{k}_{t}\right)=D\left(\boldsymbol{\mu}_{t}, \boldsymbol{\tau}_{t}, \boldsymbol{\alpha}_{t} ; \mathbf{k}_{t}\right)
$$

and the corresponding Malmquist economic output quantity index is

$$
M^{m s}\left(\boldsymbol{\mu}_{t 2}, \boldsymbol{\tau}_{t 2}, \boldsymbol{\mu}_{t 1}, \boldsymbol{\tau}_{t 1} ; \boldsymbol{\alpha}_{0}, \mathbf{k}_{t}\right)=D\left(\boldsymbol{\mu}_{t 2}, \boldsymbol{\tau}_{t 2}, \boldsymbol{\alpha}_{0} ; \mathbf{k}_{t}\right) / D\left(\boldsymbol{\mu}_{t 1}, \boldsymbol{\tau}_{t 1}, \boldsymbol{\alpha}_{0} ; \mathbf{k}_{t}\right)
$$

The corresponding true output price aggregate is 


$$
\Gamma\left(\boldsymbol{\gamma}_{t}, \tilde{\boldsymbol{\pi}}_{t} ; \boldsymbol{\alpha}_{0}, \mathbf{k}_{t}\right)=R^{*}\left(\boldsymbol{\alpha}_{0}, \boldsymbol{\gamma}_{t}, \tilde{\boldsymbol{\pi}}_{t} ; \mathbf{k}_{t}\right)
$$

and the corresponding Konüs true financial output price index is

$$
\Gamma^{k}\left(\boldsymbol{\gamma}_{t 2}, \tilde{\boldsymbol{\pi}}_{t 2}, \boldsymbol{\gamma}_{t 1}, \tilde{\boldsymbol{\pi}}_{t 1} ; \boldsymbol{\alpha}_{0}, \mathbf{k}_{t}\right)=R^{*}\left(\boldsymbol{\alpha}_{0}, \boldsymbol{\gamma}_{t 2}, \tilde{\boldsymbol{\pi}}_{t 2} ; \mathbf{k}_{t}\right) / R^{*}\left(\boldsymbol{\alpha}_{0}, \boldsymbol{\gamma}_{t 1}, \tilde{\boldsymbol{\pi}}_{t 1} ; \mathbf{k}_{t}\right)
$$

The duality results are

$$
D\left(\boldsymbol{\mu}_{t}, \boldsymbol{\tau}_{t}, \boldsymbol{\alpha}_{0} ; \mathbf{k}\right)=\max _{\left\{\gamma_{t}, \tilde{\pi}_{\mathbf{t}}\right\}}\left\{\gamma_{t}^{\prime} \boldsymbol{\mu}_{\mathbf{t}}+\tilde{\boldsymbol{\pi}}_{t}^{\prime} \boldsymbol{\tau}_{t}: R^{*}\left(\boldsymbol{\alpha}_{0}, \boldsymbol{\gamma}_{t}, \tilde{\boldsymbol{\pi}}_{t} ; \mathbf{k}_{t}\right)=1\right\}
$$

and

$$
R^{*}\left(\boldsymbol{\alpha}_{0}, \boldsymbol{\gamma}_{t}, \tilde{\boldsymbol{\pi}}_{t} ; \mathbf{k}_{t}\right)=\max _{\left\{\boldsymbol{\mu}_{t}, \boldsymbol{\tau}_{t}\right\}}\left\{\gamma_{t}^{\prime} \boldsymbol{\mu}_{\mathbf{t}}+\tilde{\boldsymbol{\pi}}_{t}^{\prime} \boldsymbol{\tau}_{t}: D\left(\boldsymbol{\mu}_{t}, \boldsymbol{\tau}_{t}, \boldsymbol{\alpha}_{\mathbf{0}} ; \mathbf{k}_{\mathbf{t}}\right)=1\right\}
$$

\section{Value Added from Financial Intermediation}

Partition the financial intermediary's input vector $\boldsymbol{\alpha}_{t}$ so that $\boldsymbol{\alpha}_{t}=\left(\boldsymbol{\alpha}_{1 t}^{\prime}, \boldsymbol{\alpha}_{2 t}^{\prime}\right)^{\prime}$, where $\boldsymbol{\alpha}_{1 t}$ is the quantities of primary inputs to the financial intermediary, and $\boldsymbol{\alpha}_{2 t}$ is quantities of intermediate inputs.

Partition the factor-price vector correspondingly so that $\boldsymbol{\beta}_{t}=\left(\boldsymbol{\beta}_{1 t}^{\prime}, \boldsymbol{\beta}_{2 t}^{\prime}\right)^{\prime}$. Then the financial intermediary's technology can be written as

$$
M_{t}^{s}=g\left(\boldsymbol{\alpha}_{1 t}, \boldsymbol{\alpha}_{2 t}\right)
$$

Let the firm's maximum variable profit level at given $\boldsymbol{\alpha}_{1 t}$ be

$$
V_{t}=V\left(\boldsymbol{\alpha}_{1 t}, \boldsymbol{\beta}_{2 t}, \boldsymbol{\gamma}_{t}, \tilde{\boldsymbol{\pi}}_{t}\right)
$$

which is the firm's variable profit function conditional upon $\boldsymbol{\alpha}_{1 t}$. As a function of $\boldsymbol{\alpha}_{1 t}$ at fixed prices, $V$ has all of the usual properties of a neoclassical production function. Sato (1975) calls 


$$
V_{t_{0}, t_{1}}=V\left(\boldsymbol{\alpha}_{1 t_{0}}, \boldsymbol{\beta}_{2}^{*}, \boldsymbol{\gamma}^{*}, \tilde{\boldsymbol{\pi}}_{t}^{*}\right) / V\left(\boldsymbol{\alpha}_{1 t_{1}}, \boldsymbol{\beta}_{2}^{*}, \boldsymbol{\gamma}^{*}, \tilde{\boldsymbol{\pi}}_{t}^{*}\right)
$$

the true index of real value added, which depend upon the selection of the reference prices $\left(\boldsymbol{\beta}_{2}^{*}, \gamma^{*}, \tilde{\boldsymbol{\pi}}^{*}\right)$

To provide a nonparametric (statistical) approximation to (43), assume constant returns to scale. Also assume that $V$ is translog, and select $\left(\boldsymbol{\beta}_{2}^{*}, \boldsymbol{\gamma}^{*}, \tilde{\boldsymbol{\pi}}^{*}\right)$ to be the geometric means of those prices in periods $t_{0}$ and $t_{1}$. Using Diewert (1980a, p. 459), it follows that (43) equals the discrete Divisia quantity index for aggregating over the primary inputs.

The need to select the reference prices $\left(\boldsymbol{\beta}_{2}^{*}, \gamma^{*}, \tilde{\boldsymbol{\pi}}^{*}\right)$ becomes unnecessary if and only if $g$ is separable, so that (41) can be written

$$
M_{t}^{s}=G\left(\varphi\left(\boldsymbol{\alpha}_{1 t}\right), \boldsymbol{\alpha}_{2 t}\right) .
$$

In that case, $V$ can be written

$$
V_{t}=V_{1}\left(\boldsymbol{\alpha}_{1 t}\right) V_{2}\left(\boldsymbol{\beta}_{2 t}, \boldsymbol{\gamma}_{t}, \tilde{\boldsymbol{\pi}}_{t}\right)
$$

So clearly

$$
V_{t_{0}, t_{1}}=V_{1}\left(\boldsymbol{\alpha}_{1 t_{0}}\right) / V_{1}\left(\boldsymbol{\alpha}_{1 t_{1}}\right)
$$

which does not depend upon reference prices. The function $V_{1}$ has all of the properties of a conventional neoclassical production function. However, in this case $\varphi\left(\boldsymbol{\alpha}_{1 t}\right)$ is itself a category subproduction function, so we can more directly define the value-added index to be

$$
V_{t_{0}, t_{1}}^{*}=\varphi\left(\boldsymbol{\alpha}_{1 t_{0}}\right) / \varphi\left(\boldsymbol{\alpha}_{1 t_{1}}\right)
$$


If $\varphi$ is translog, then the discrete Divisia index is exact for either (46) or (47), so the discrete Divisia index provides a second-order approximation for $V_{t_{0}, t_{1}}^{*}$ or $V_{t_{0}, t_{1}}$ for any $\varphi$. In continuous time, the Divisia index is always exact for $\varphi\left(\boldsymbol{\alpha}_{1 t}\right)$, which is value added.

By accounting convention, "double deflation" requires the very restrictive assumption that (44) can be written in the form

$$
M_{t}^{s}=\varphi_{1}\left(\boldsymbol{\alpha}_{1 t}\right)+\varphi_{2}\left(\boldsymbol{\alpha}_{2 t}\right)
$$

Clearly $\varphi_{1}\left(\boldsymbol{\alpha}_{1 t}\right)$ is value added, since it is added to $\varphi_{2}\left(\boldsymbol{\alpha}_{2 t}\right)$ to get $M_{t}^{s}$. In that case, Sims (1969) has proved that value added is measured exactly by a Divisia index.

\section{Data Sources}

The credit card transactions services can be measured by the transactions volumes summed over four sources: Visa, MasterCard, American Express, and Discover. Our theory does not apply to debit cards, or to store cards, or to charge cards not providing a line of credit. ${ }^{9}$ Barnett, Chauvet, LeivaLeon, and Su (2016) acquired the volumes from the firms' annual reports and seasonally adjusted them by the Census X-13ARIMA-SEATS program. The start date is the quarter during which those credit card firms went public and the annual reports became available. The contemporaneous transactions volumes do not include the carried forward rotating balances resulting from transactions during prior periods. ${ }^{10}$ The credit card interest rates are available from the Federal Reserve Board's data on all

\footnotetext{
${ }^{9}$ Although not currently incorporated into this research, the relevancy of debit cards to future research is established by David, Abel, and Patrick (2016).

${ }^{10}$ Credit limits are not explicitly considered in our current model, since we do not have a way to untangle the effect of those constraints on contemporaneous transactions volumes from the effect on the carried forward rotating balances associate with previous period's transactions.
} 
commercial bank credit card accounts, including those not charged interest, since paid off within the

month. ${ }^{11}$

In classical economics, the benchmark asset is a secured pure investment. In contrast, $\bar{e}_{j s}$ is not the interest rate on a secured asset and is subject to substantial default and fraud risk. ${ }^{12}$ Hence, $\bar{e}_{j s}$ can be higher than the benchmark asset rate, and historically has always been much higher than the benchmark asset rate. ${ }^{13}$

It is important to recognize that the decision problem we model is not of a single economic agent, but rather of a "representative bank" and a "representative consumer," aggregated over all consumers and all banks. All quantities are therefore averaged over all consumers and banks. This modeling assumption is particularly important in understand the credit card quantities and interest rates relevant to this theory. About $20 \%$ of credit card holders in the United States do not pay explicit interest on credit card balances, since those credit card transactions are paid off by the end of the period. But the $80 \%$ who do pay interest pay very high interest rates. ${ }^{14}$ The Federal Reserve provides two interest rate series for credit card debt. One, $\bar{e}_{j s}$, includes interest only on accounts that do pay interest to the credit card issuing banks, while the other series, $e_{j s}$, includes the approximately $20 \%$ that do not pay interest.

\footnotetext{
${ }^{11}$ This interest rate includes those credit card accounts not assessed interest, and hence is lower than the Federal Reserve's supplied interest rates on accounts assessed interest. This imputation includes only explicit interest paid, averaged over all credit card accounts.

${ }^{12}$ See, e.g., Butaru, Chen, Clark, Das, Lo, and Siddique (2016).

${ }^{13}$ Barnett, Chauvet, Leiva-Leon, and Su (2016) follow the Center for Financial Stability (CFS) and the Bank of Israel in using the short-term bank loan rate as a proxy for the benchmark rate. That interest rate has always exceeded the interest rate paid by banks on deposit accounts and on all other monetary assets used in the CFS Divisia monetary aggregates, and has always been lower than the Federal Reserve's reported average interest rate charged on credit card balances. However, it is important to keep in mind that the benchmark rate in theory is the rate of return on an owned asset, pure capital. Since that asset is owned by its investors, it is fully secured. While short term bank loans are assets to banks, some are unsecured. For detailed information on CFS data sources, see Barnett, Liu, Mattson, and Noort (2013).

An alternative proxy for the benchmark interest rate has been proposed by Fixler and Zieschang $(2016 a, b)$. They advocate using the financial firm's overall funding portfolio as the benchmark asset and the cost of funding rate as the benchmark rate. In macroeconomic research, we currently favor consistency with the CFS convention, the short-term bank loan rate, which is easily available from the Federal Reserve. But we recognize that the Fixler and Zieschang $(2016 a, b)$ proposal is very reasonable.

${ }^{14}$ The following statement is from www.motherjones.com/kevin-drum/2011/10/americans-are-clueless-abouttheir-credit-card-debt. "In the four working age categories, about $50 \%$ of households think they have outstanding credit card debt, but the credit card companies themselves think about $80 \%$ of households have outstanding balances." Since these percentages are of total households, including those having no credit cards, the percent of credit card holders paying interest might be even higher.
} 
The latter interest rate is thereby lower, since it is averaged over interest paid on both categories of accounts. Since the representative consumer is aggregated over all consumers, $e_{j s}$ is always less than $\bar{e}_{j s}$ for all $j$ and $s$. The interest rate on rotating credit card balances, $\bar{e}_{j s}$, is paid by all consumers who maintain rotating balances on credit cards. But $e_{j s}$ is averaged over both those consumers who maintain such rotating balances and hence pay interest on contemporaneous credit card transactions (volumes) and also over those consumers who pay off such credit card transactions before the end of the period, and hence do not pay explicit interest on the credit card transactions. The Federal Reserve provides data on both $\bar{e}_{j s}$ and $e_{j s}$. Although $e_{j s}$ is less than $\bar{e}_{j s}, e_{j s}$ also has always been higher than the benchmark rate. ${ }^{15}$

The expected interest rate, $e_{j s}$, can be explicit or implicit, and applies to the aggregated representative consumer. For example, an implicit part of that interest rate could be in the form of an increased price of the goods purchased or in the form of a periodic service fee or membership fee. But Barnett, Chauvet, Leiva-Leon, and Su (2016) use only the Federal Reserve's average explicit interest rate series, which is lower than the one that would include implicit interest. Nevertheless, that downward biased explicit rate of return to credit card companies, $e_{j s}$, aggregated over consumers, tends to be very high, far exceeding $R_{S}$, even after substantial losses from fraud.

\section{Results}

The concept of "inside money" produced by the services of banks and associated with the value added in banking, has had an historic role in the literature about monetary aggregation, monetary transmission, and monetary policy. See, e.g, Cavalcanti and Wallace (1996), Spencer (1974), Brunner and Meltzer (1967,1990), Meltzer (1969), Tobin (1963), Gurley and Shaw (1960), Johnson (1969), Pesek and Saving (1967), Fisher (1961), Friedman and Schwartz (1963), and Cagan (1956). Even the early literature on real business cycle theory $(\mathrm{RBC})$, which sought to remove money from macroeconomic models, also considered the separation of inside money from outside money to be central to RBC's

\footnotetext{
${ }^{15}$ Barnett, Chauvet, Leiva-Leon, and Su (2016) use the Federal Reserve data sources for both $\bar{e}_{j s}$ and $e_{j s}$, as is customary in most applied macroeconomic research. But the supply side theory presented in this paper is potentially relevant to the national accounts, which are based upon very careful consideration of bank balance sheets and detailed data sources, as pointed out to us by Kimberley Zieschang. For such purposes, it might be appropriate to explore in more detail the Federal Reserve's treatment of write-offs for fraud and default, which have much to do with the high interest rates charged on credit card balances. For example, fraud almost exclusively affects the earnings by banks on current period credit card volumes, while default more heavily affects rotating balance earnings than current period transaction volume earnings.
} 
empirical research. ${ }^{16}$ But as was made clear by the research of Pesek and Saving, Gurley and Shaw, and the early Shadow Open Market Committee under Brunner and Meltzer, macroeconomic models that omit money, especially inside money, are implicitly assuming that banks produce no value added, and hence should receive no profit in the economy's general equilibrium. Under that implicit assumption, privately owned banks would not exist. Although there has been growing research into the inclusion of value added in banking into GDP, adequate imputation does not yet exist in GDP data. See, e.g., Fixler and Zieschang. As a result, early research concluding that production of inside money by banks should be included in macroeconomic models remains relevant.

While the central role of the separation of inside from outside money in much of that literature has long been clear, the transmission mechanism to final targets from changes in inside and outside money has been the subject of much disagreement, along with how to measure inside and outside money. Regarding that history, Meltzer (1969, p. 29) has explained as follows:

"One source of confusion in monetary theory is the use of different terminology to refer to the same or very similar magnitudes. Outside money is called government demand debt or deadweight debt by Tobin, high-powered money by Friedman, Schwartz, and Cagan, the monetary base by Brunner and myself, the source base by Anderson, Jordan, and others at the Federal Reserve Bank of St. Louis, and money by Irving Fisher. Outside money plus inside money is called the circulating media by Irving Fisher, and inside money is called deposits by most monetary economists." ${ }^{17}$

Despite the differences, observe that inside money plus outside money equals total money, according to the accounting conventions on which that literature is based. ${ }^{18}$ Also observe that Brunner and Meltzer $(1967,1990)$ and thereby the early literature and advocacy from the Shadow Open Market committee viewed the monetary base to be outside money. Hence, according to that view, inside money equals a simple sum monetary aggregate minus the monetary base. At the present time, the only concept of outside money that is mentioned in Meltzer's (1969) survey paper and is available from official Federal Reserve data is the monetary base.

\footnotetext{
${ }^{16}$ See, e.g, King and Plosser (1987) and Chari, Christiano, and Eichenbaum (1995).
}

\footnotetext{
${ }^{17}$ For the references mentioned in that quotation, see Tobin (1963), Friedman and Schwartz (1963), Cagan (1956), Brunner and Meltzer (1967,1990), Anderson and Jordan (1968), and Fisher (1961).

${ }^{18}$ This accounting identity is not relevant to our measure of inside money, equation (32), which measures service flow, not stock.
} 
Meltzer's survey remains relevant today. According to the Wikipedia's entry for "monetary base," the "monetary base is also called base money, money base, high-powered money, outside money, central bank money, and narrow money (in the UK)." According to Hummelon (2015), "prior to the financial crisis, the monetary base consisted entirely of outside money." Hummelon advocated adjusting the monetary base to be the "outside base," Hence there is reason to be skeptical of the outside money interpretation of the monetary base, following the financial crisis; but the Federal Reserve does not provide data on a measure of the outside base. Using the available Federal Reserve source, the conventional measure of inside money remains Federal Reserve reported simple sum money minus the Federal Reserve's reported monetary base.

Although the monetary base and inside money have played a major role in the literature on monetary economics for over a century, there have always been reasons for concern about the use of the monetary base as outside money in the monetary transmission mechanism. For example, during the Great Depression, the monetary base continued growing, even though the money supply was crashing. This paradox induced Milton Friedman to emphasize measures of the total money supply, while rarely mentioning the monetary base. In contrast, Brunner, Meltzer, the Shadow Open Market Committee, and the St. Louis Federal Reserve Bank, advocating a different monetarist tradition, took the monetary base very seriously, as did early researchers on real business cycle theory.

But as emphasized by Hummelon, it has become difficult to take seriously the monetary base, since the financial crisis occurred and led to the Great Recession. In addition, the simple sum broad monetary assets, M3 and M4, have fallen into disrepute and no longer are provided by the Federal Reserve. We agree that the accounting convention approach to producing inside money and broad monetary aggregates are seriously defective. In the case of $M 3$ and $M 4$, the problem is that they impute too much weight to distant substitutes for money. Even the traditionally monetarist Shadow Open Market Committee is increasingly recognizing these facts, as evidenced by the fact that Peter Ireland, who has been a Member of the Shadow Open Market Committee since 2011, uses the CFS Divisia monetary aggregates in his research. See, e.g, Belongia and Ireland (2014;2015a,b;2016).

Now that the CFS is providing inside money aggregates produced from our microeconomic supply-side aggregation theory, we can investigate whether our equation (32) can produce useful inside money data, even though inside money aggregates produced from accounting conventions have become severely defective. We investigate the implications of our theory and of the prior accounting 
based approach using the CFS monthly data for July 2006 through September $2017 .{ }^{19}$ We begin this investigation by displaying conventional simple sum $\mathrm{M} 1$ and the monetary base, as provided by the Federal Reserve. Those plots are displayed in Figure 1. The resulting implied inside money aggregate, computed by subtracting the monetary base from $\mathrm{M} 1$ is displayed in Figure 2. Unlike $\mathrm{M} 2$, which includes the shadow banking services of monetary market mutual funds, M1 contains only banking components. As evident from Figure 2, the conventional accounting measure of commercial bank inside money production at the M1 level of aggregation has become so severely defective as to be impossible to take seriously. During a period that privately produced inside money has been growing rapidly and providing most of the economy's monetary services, the conventional measure says it was not increasing at all up until the financial crisis, and then went negative. These results from the conventional accounting approach are not at all credible, because they imply that banks' narrow money production has been supplying no value added to the economy since the financial crisis, and hence in equilibrium should disappear from the economy.

A possible source of this problem could be sweeps, which bias downwards the Federal Reserve's reported demand deposit data. Since the Federal Reserve no longer provides data on sweeps, the Center for Financial Stability (CFS) must infer sweeps from an econometric model. Figure 3 provides the Figure 1 plots, but with M1 sweep-adjusted by the CFS. While the sweep adjustment helps, the results remain not credible, especially since the financial crises, after which the traditional measure of inside money still implies that bank produced M1 services to the economy had disappeared, and briefly became negative. Some economists, being aware of the problems associated with the accounting monetary base measures, have advocated instead the use of nonborrowed reserves as a proxy for outside money. Paul Volcker advocated use of nonborrowed reserves as the instrument of policy, rather than the monetary base. The merits of the nonborrowed reserves measure have been explored in many published papers, such as Chari, Christiano, and Eichenbaum (1995). But Figure 4 displays the fact that nonborrowed reserves, as reported by the Federal Reserve, are seriously defective. Observe that for a brief time they became negative. Negative values of nonborrowed reserves, defined to be total reserves minus borrowed reserves, is an oxymoron. ${ }^{20}$

\footnotetext{
${ }^{19}$ The CFS credit-card-augmented inside money Divisia aggregates, produced from our equation (32), are available online at http://www.centerforfinancialstability.org/amfm_augmented.php.

${ }^{20}$ The reason for this problem is that the Federal Reserve now includes within borrowed reserves some bank borrowing not being held in reserves.
} 
In dramatic contrast, observe Figure 5, which displays the new CFS M1 inside money measure, produced from our equation (32). That figure indicates the steady growth of services provided to the economy by private banks during the sample period. The credit-card-augmented inside-money financial services aggregates, computed from equation (32), are available to the public from the Center for Financial Stability in New York City and posted online at www.centerforfinancialstability.org/amfm.php. The aggregates are available at seven levels of aggregation, called M1, MZM, M2M, M2, ALL, M3, and M4-. None of those inside money aggregates contain currency, which is relevant to demand side monetary aggregation, but not to supply side inside money aggregation. In accordance with our theoretical model, excess reserves are inputs to bank technology, not produced output supplied to the economy by the work of private banks. The demand side aggregate, M4, differs from M4- by inclusion of Treasury bills, which are also not part of the economy's privately produced inside money. ${ }^{21}$

In addition to making available the inside money aggregates to the public online, the Center for Financial Stability supplies Divisia monetary aggregates through a public release. That monthly release provides the demand side Divisia monetary aggregates at all available levels of aggregation, but the supply side inside monetary aggregates are currently planned to be included in those releases only for the broadest supply-side inside-money aggregate, M4-. That aggregate not only includes bank produced inside money services, but also much of the economy's shadow banking inside money services, properly weighted. The data supplied in the releases are also available to Bloomberg Terminal users. ${ }^{22}$ We have

\footnotetext{
${ }^{21}$ Our broadest inside money measure, M4-, does not include currency or Treasury bills, which are not produced by the work of private financial firms. However, M4- does include the services to the economy of much shadow banking, including money market mutual funds, repurchase agreements, and commercial paper. Whether to include all commercial paper as a shadow banking output is controversial. The CFS does so, since most commercial paper is supplied to customers by banks and other financial firms. For example, the Wikipedia entry on Shadow Banking System contains this statement: "Banks by far are the largest issuers of commercial paper." But Bernanke (2013) advocated inclusion of only asset-backed commercial paper (ABCP) conduits in shadow banking. We adopt the CFS inclusion of all commercial paper in inside money. The current version of our theoretical model does not provide a means of distinguishing between $A B C P$ and other commercial paper.

${ }^{22}$ Access on terminal with the following steps:
} \{ALLX DIVM \} 
provided a plot of that broadest inside money aggregate in Figure 6. Comparison with the nominal GDP plot in Figure 7 and unemployment rate in Figure 8 indicates the usefulness of our inside monetary services aggregate as an indicator of the state of the economy and for the other applications of inside money, as contemplated in the historic literature on that subject. ${ }^{23}$ In fact with the dramatic growth of private sector financial firms in recent years, including both private banking and shadow banking, much policy and regulation, such as Dodd Frank and the Federal Reserve's "unconventional monetary policies," have focused on that sector, which produces inside money as its output.

It is not possible to provide the conventional accounting-based measure of M4- inside money, since the Federal Reserve no longer provides simple sum M3 or M4 or their components. We agree with the Federal Reserve's decision to discontinue simple sum M3 and M4, which imputes excessive weight to distant substitutes for money, treated as perfect substitutes for demand deposits. For that reason, the CFS also does not provide simple sum M3 or M4. ${ }^{24}$

\{ECST T DIVMM4IY\}

\{ECST $\}$--> 'Monetary Sector' --> 'Money Supply' --> Change Source in top right to 'Center for Financial Stability \{ECST S US MONEY SUPPLY\} --> From source list on left, select 'Center for Financial Stability'

${ }^{23}$ The GDP data are quarterly, rather than monthly, and end in the second quarter of 2017.

${ }^{24}$ Even if the CFS wanted to provide simple sum M3, M4-, or M4, those simple sum aggregates could not be provided in a competent manner. Simple sum aggregation by accounting conventions requires data on consolidated components. Those consolidated components are not available from any sources, since the Federal Reserve discontinued supplying them. For Divisia aggregation, based on microeconomic theory, market data on components are needed, and the CFS is able to acquire those data from subscription services. 
Figure 1: Federal Reserve M1 and Monetary Base, from St. Louis Federal Reserve FRED Database, billions of dollars.

FRED M1 vs Monetary Base (Semi-Log Scale)

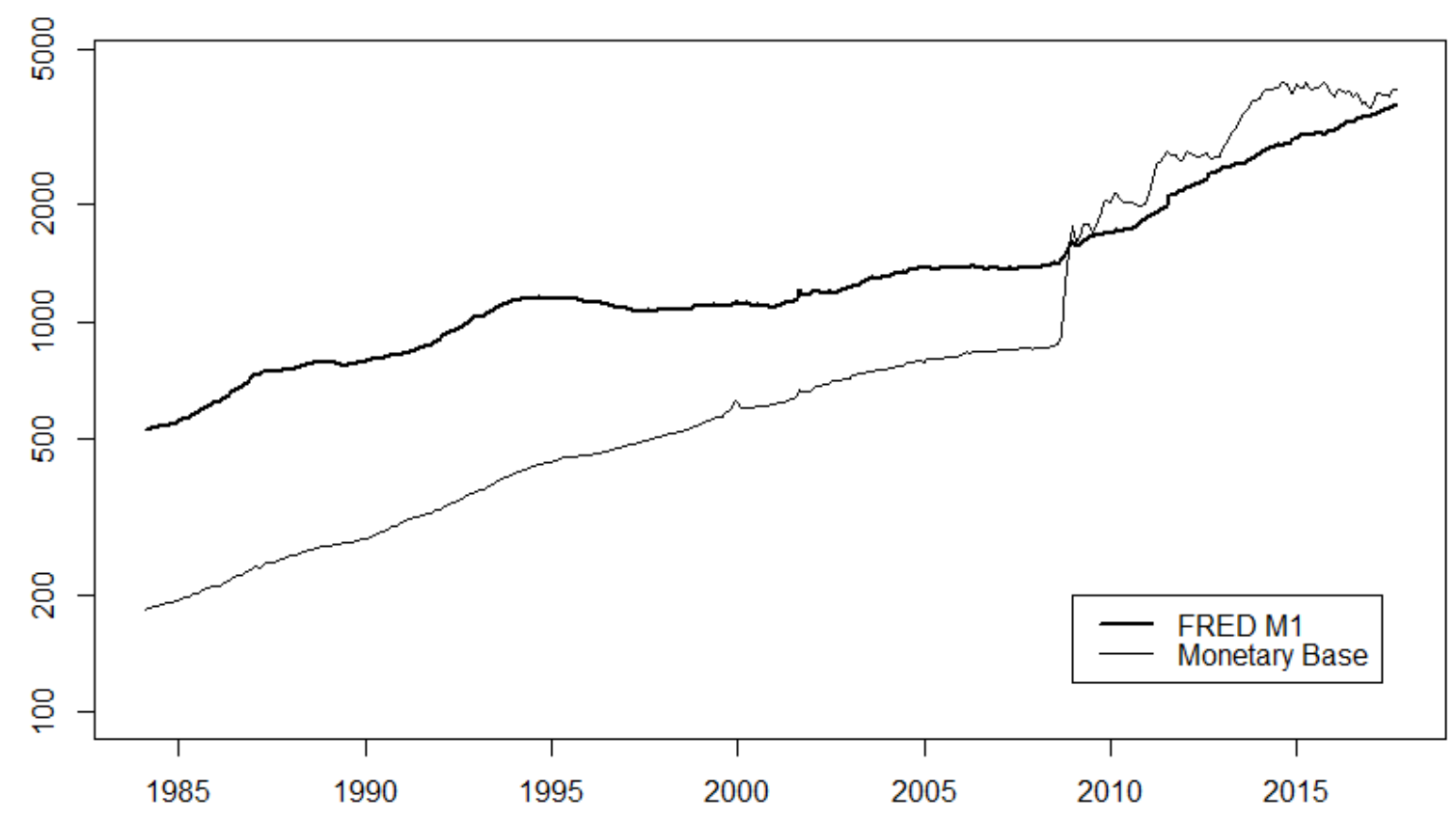


Figure 2: Conventional Accounting M1 Inside Money: Federal Reserve M1 minus Monetary Base, billions of dollars.

FRED M1 Minus Monetary Base

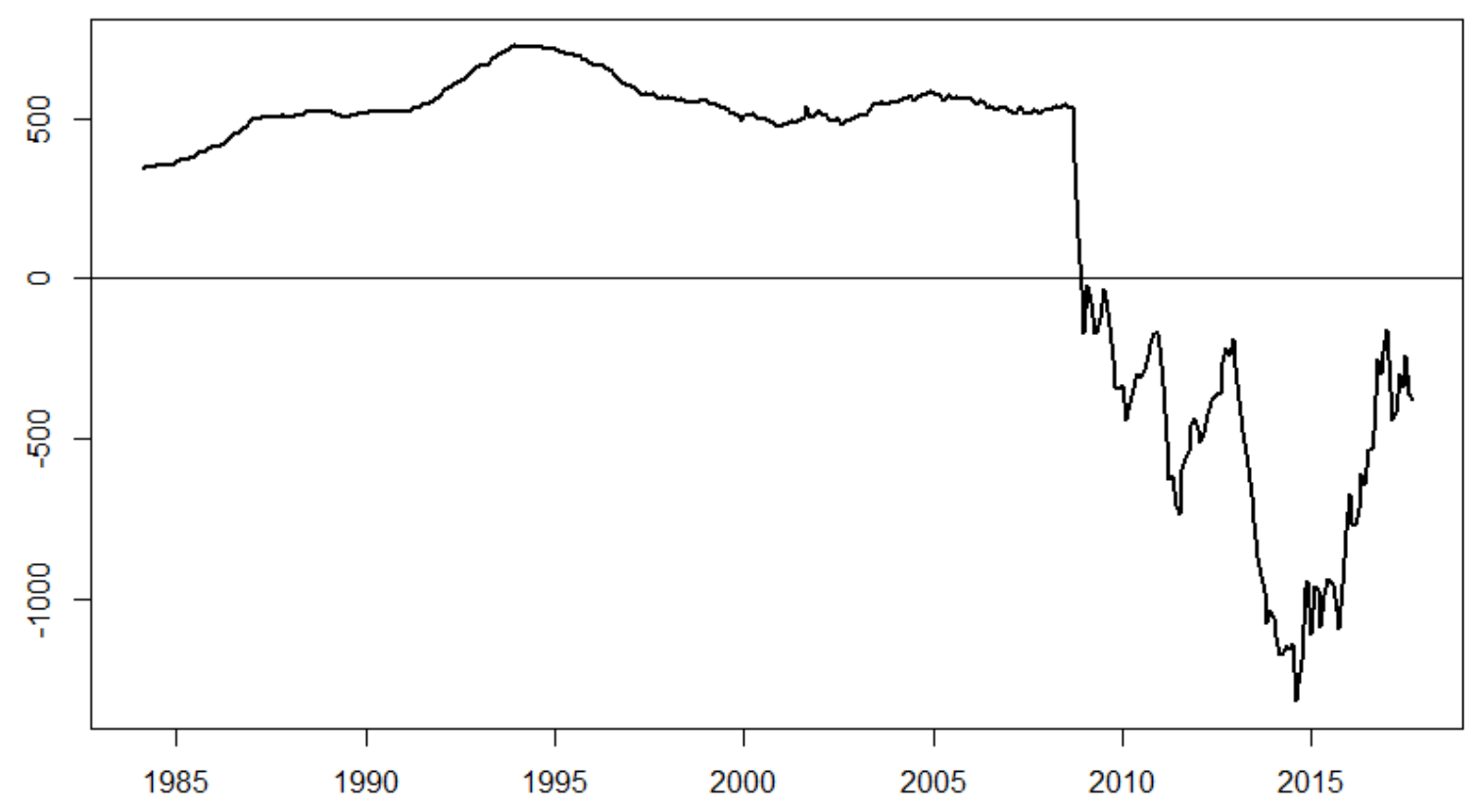


Figure 3: CFS Sweep Adjusted Simple Sum M1 and Federal Reserve Monetary Base, billions of dollars.

CFS M1 vs Monetary Base (Semi-Log Scale)

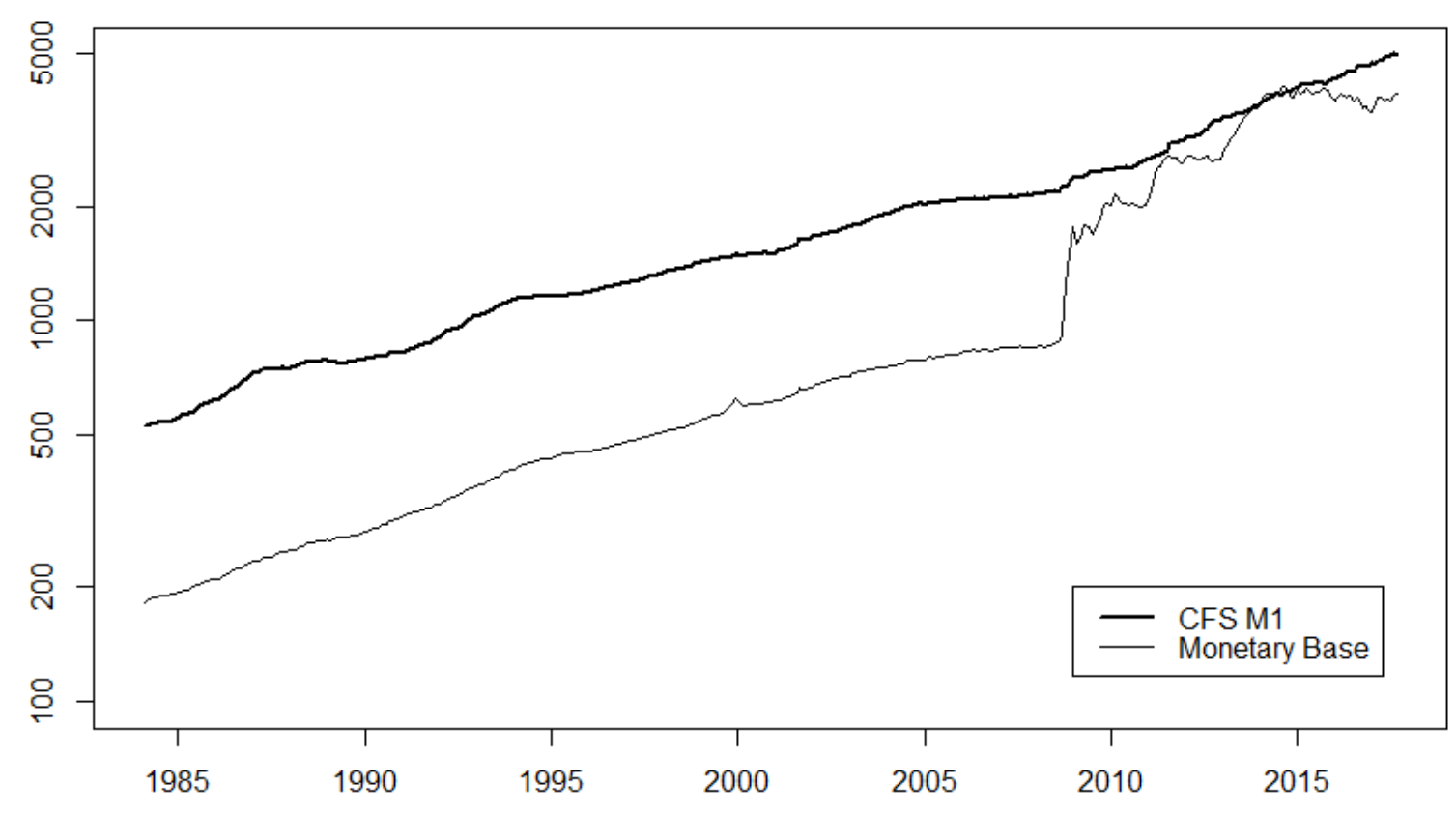


Figure 4: Federal Reserve Non-Borrowed Reserves from St. Louis Federal Reserve Bank FRED Database, billions of dollars

Non-Borrowed Reserves

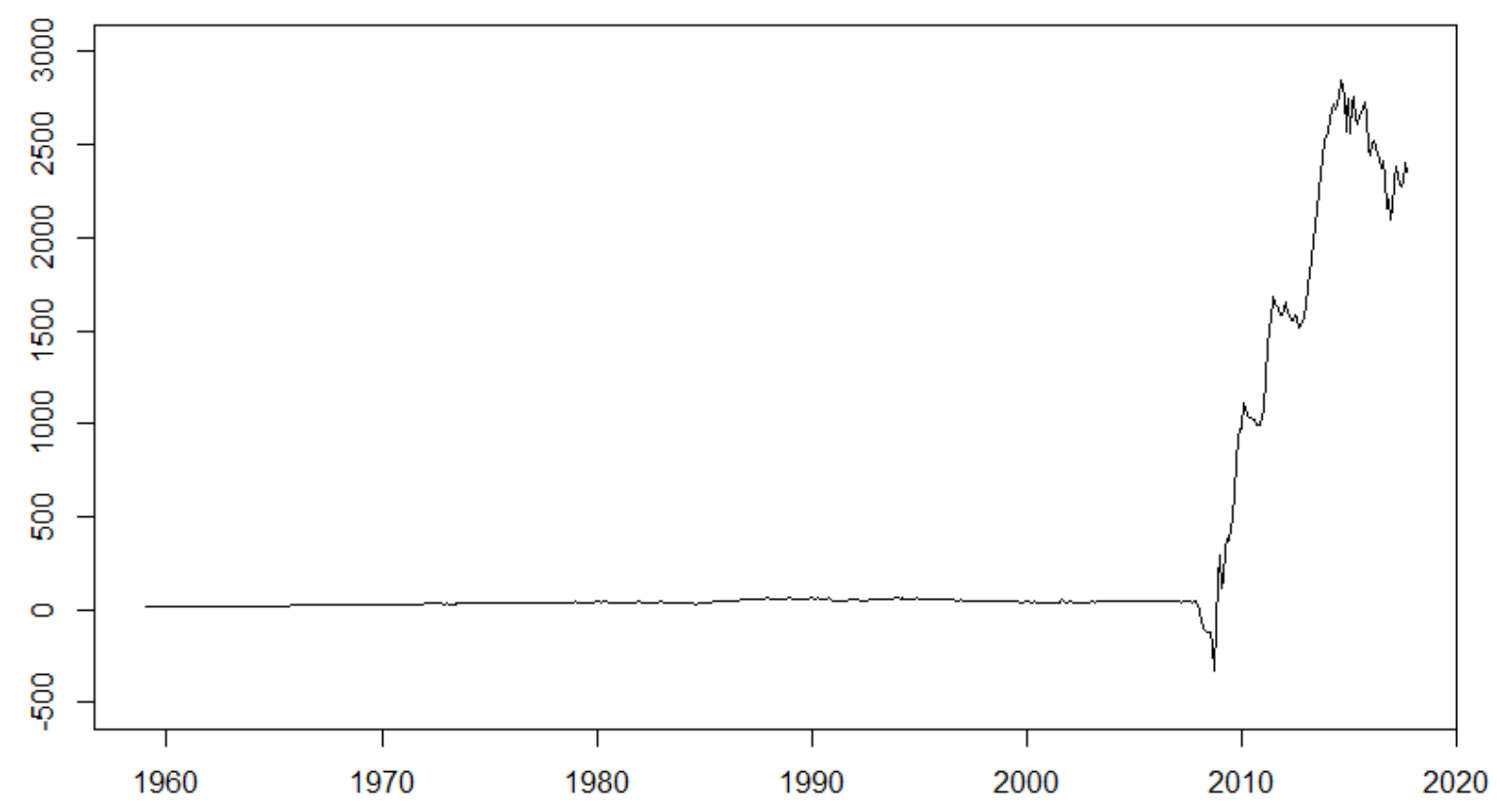


Figure 5: CFS Divisia Credit-Card-Augmented M1 Inside Money, index number normalized to equal 100 in July 2006.

M1AI (Semi-Log Scale)

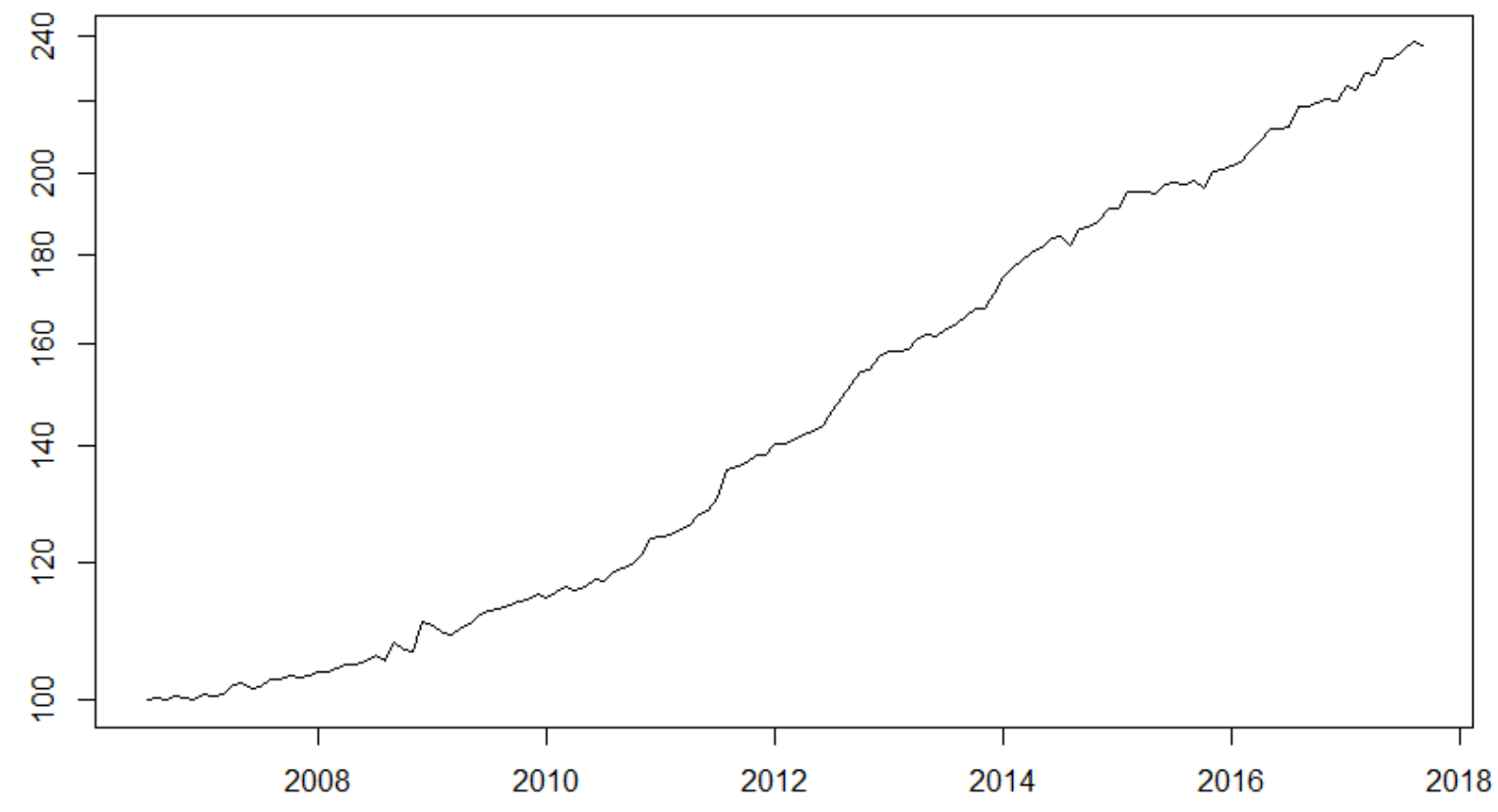


Figure 6: CFS Divisia Credit-Card-Augmented M4- Inside Money, index number normalized to equal 100 in July 2006.

M4AI- (Semi-Log Scale)

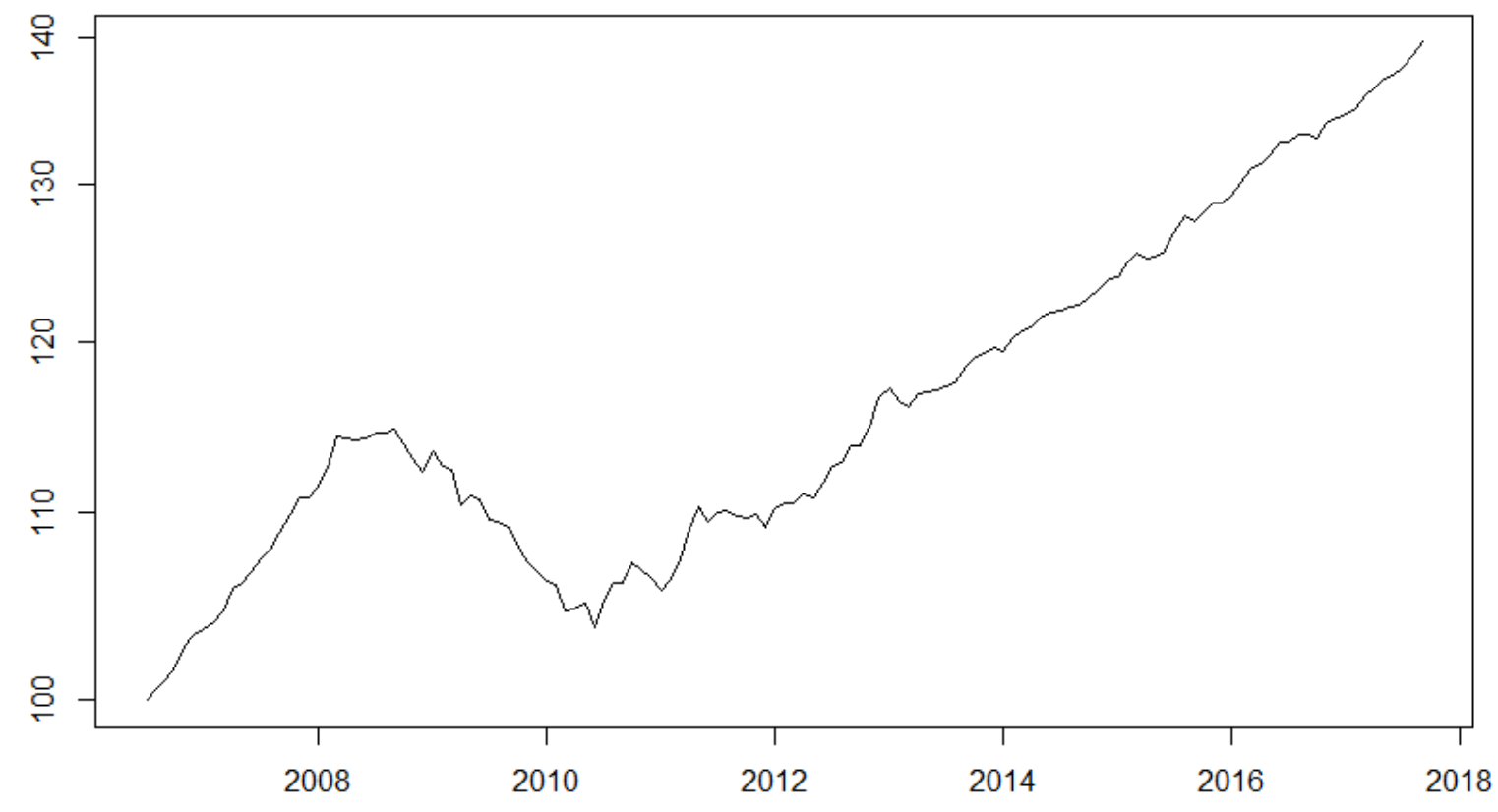


Figure 7: Nominal GDP, billions of dollars

Nominal GDP (Semi-Log Scale)

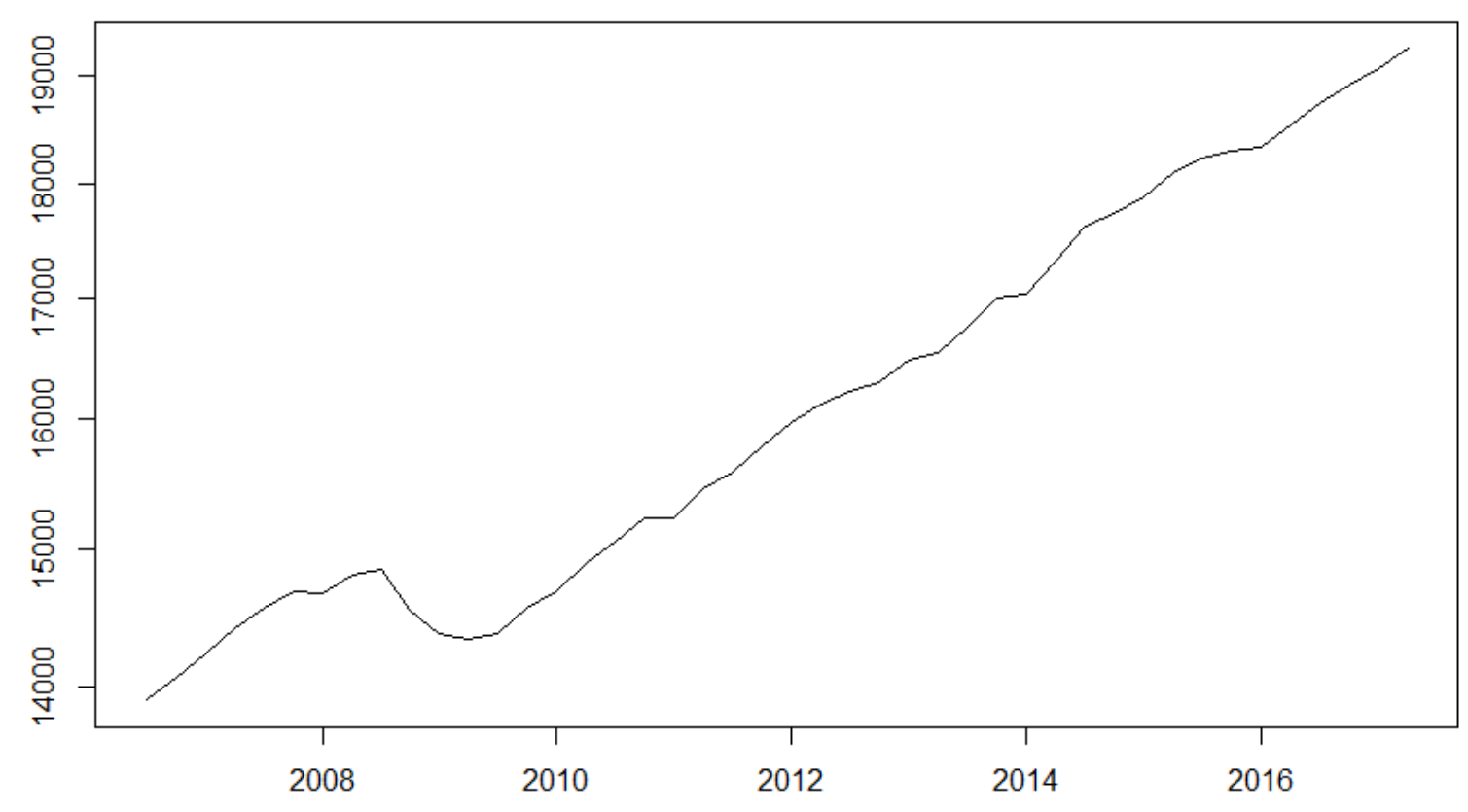


Figure 8: Unemployment rate, percent

Civilian Unemployment Rate

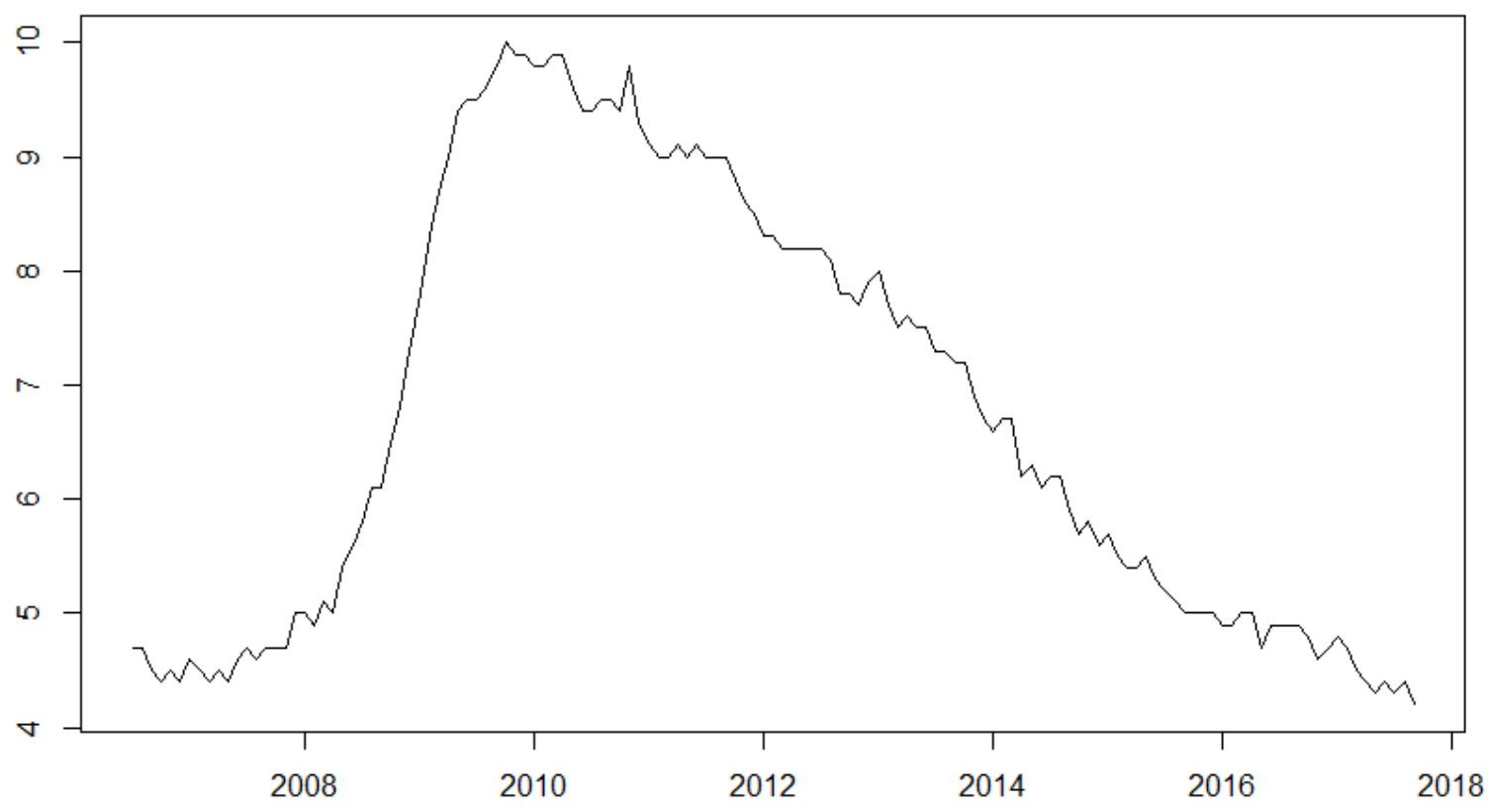




\section{Conclusion}

In this paper a monetary services production model of financial firms is employed to investigate supply-side monetary aggregation, augmented to include the credit card transactions services produced by those firms. Financial firms are viewed as producing monetary services and credit card transactions services as outputs through financial intermediation. The financial firms' outputs produce liquidity services related to their role in the transaction technology underlying the payment mechanism in the economy.

Our results indicate the following conclusions. Financial firm outputs of demand deposits, time deposit services, and credit card transactions services can be aggregated to produce an inside-money output aggregate, which then enters an aggregate services supply function for the financial firm. Currency is not included in that aggregate, since excess reserves are an input to the technologies of financial firms, not an output. Treasury bills are also excluded from the inside money aggregates, since the liquidity services supplied to the economy from Treasury bills are not a source of economic value added imputable to the work of private financial firms. The user cost formula for supplied monetary assets differs from the demand side user cost formula, because of the regulatory wedge produced by the existence of reserve requirements, imposing an implicit tax on banks. ${ }^{25}$ When all outputs are separable from inputs, there exists a single inside-money output aggregate, and hence the use of a single output aggregate can be justified in the formulation and estimation of the financial firm's production technology.

The theory can be implemented to investigate the role of financial intermediaries in the production of inside money, which plays a role in the transmission mechanism of monetary policy, and

\footnotetext{
${ }^{25}$ In recent years, that implicit tax has become negligible, because of sweeps, low interest rates, and payment of interest on reserves. But even during the 1970s, when that implicit tax was very high, Barnett, Hinich, and Weber (1986) showed that the effect of that tax on the Divisia monetary aggregates was statistically insignificant.
} 
also to produce an indicator of the monthly state of the economy. Data on GDP cannot provide that monthly indicator value, since GDP is available only quarterly. Using equation (32), we provide our inside money aggregate in a manner fully consistent with our microeconomic theory. Earlier results on the monetary policy transmission mechanism based on the correlation between simple sum inside money and final targets are not even relevant to results acquired by empirical implementation of this model or its extensions. In particular, our financial-firm inside-money measure is very different from prior measures of inside money or their supply functions, which had been fundamental to much classical and monetarist economics for a century. The conventional accounting-based inside money measure has become disreputable within the profession and at central banks for reasons which we find to be completely justifiable. But our measure, derived directly from microeconomic theory to measure service flows, behaves very differently from the former accounting measures and remains potentially very informative. Our results are directly relevant to measures of value added by financial intermediation, through the theory in our Section $8 .{ }^{26}$

Much work remains to be done, including theoretical generalizations with weakened assumptions and empirical applications requiring specification and estimation of financial firm technology. ${ }^{27}$ The most challenging generalizations could permit incomplete contingent claims markets and asymmetric information to explain the appearance of risk averse behavior by financial firms. ${ }^{28}$ On the consumer demand side, Barnett and Su (2016) have derived the formula needed to adjust the credit-

\footnotetext{
${ }^{26}$ Converting our inside money measure to value added would require separating factors of production into primary and secondary factors. While value added measures are relevant to computation of GDP and to the microeconomic theory justifying entry into the industry, inside money services are far more relevant to macroeconomic theory than value added is.

${ }^{27}$ Empirical results in this tradition, but with credit card services omitted, can be found in Barnett and Hahm (1994), Barnett and Zhou (1994), Barnett, Kirova, and Pasupathy (1995), and Hancock (1991). The econometric specifications of technology used in those studies are potentially relevant to this paper's extension, but with the relevant change of variables.

${ }^{28}$ See, e.g., Stiglitz and Weiss (1981) and Crawford, Pavanini, and Schivardi (2015) on asymmetric information and Magil and Quinzii $(2002,2008)$ on incomplete markets.
} 
card-augmented Divisia monetary aggregates for risk aversion in accordance with CCAPM. But the needed extension on the supply side is more challenging, because of the complexities of establishing incentive compatibility, when the firms' owners are not also the managers.

The theoretical and empirical problems previously associated with the inability to include credit card transactions services into financial intermediary output are solved. In addition, the ability to compute financial firm inside money, previously discredited by the use of accounting conventions disconnected from economic theory, are found now to be possible and potentially very useful, when computed as service flows derived from microeconomic aggregation and index number theory. 


\section{References}

Anderson, Leonall C. and Jerry L. Jordan (1968). "Monetary and Fiscal Actions: A Test of Their Relative Importance in Economic Stabilization," St. Louis Federal Reserve Bank Review November: 11-23.

Barnett, W. A. (1978). "The User Cost of Money," Economics Letter 1: 145-149. Reprinted in W. A. Barnett and A. Serletis (eds.), 2000, The Theory of Monetary Aggregation, North Holland, Amsterdam, chapter 1: 6-10.

Barnett, W. A. (1980). "Economic Monetary Aggregates: An Application of Aggregation and Index Number Theory," Journal of Econometrics 14: 11-48. Reprinted in W. A. Barnett and A. Serletis (eds.), 2000, The Theory of Monetary Aggregation, North Holland, Amsterdam, chapter 1: 6-10.

Barnett, W. A. (1987). "The Microeconomic Theory of Monetary Aggregation," in W. A. Barnett and K. Singleton (eds.), New Approaches to Monetary Economics, Cambridge U. Press. Reprinted in W. A. Barnett and A. Serletis (eds.), 2000, The Theory of Monetary Aggregation, North Holland, Amsterdam, chapter 3: 49-99.

Barnett, W. A. (2012). Getting It Wrong: How Faulty Monetary Statistics Undermine the Fed, the Financial System, and the Economy, MIT Press, Cambridge, MA.

Barnett, W.A. and M. Chauvet (2011). "How Better Monetary Statistics Could Have Signaled the Financial Crisis". Journal of Econometrics 161(1): 6-23.

Barnett, W. A and J. H. Hahm (1994). "Financial-Firm Production of Monetary Services: A Generalized Symmetric Barnett Variable-Profit-Function Approach," Journal of Business and Economic Statistics 12, 33-46. Reprinted in W. A. Barnett and J. Binner (eds.), 2004, Functional Structure and Approximation in Econometrics, North Holland, Amsterdam, chapter 15: 351-380.

Barnett, W. A., J. Keating, and L. Kelly (2011). "Rethinking the Liquidity Puzzle: Applications of a New Measure of Economic Money Stock," Journal of Banking and Finance 35(4): 765-1026.

Barnett, W. A. and L. Su (2016). "Risk Adjustment of the Credit-Card Augmented Divisia Monetary Aggregates," Johns Hopkins Studies in Applied Economics Working Paper No. 67. Forthcoming in Macroeconomic Dynamics. 
Barnett, W. A. and L. Su (2017). "Data Sources for the Credit-Card Augmented Divisia Monetary Aggregates," in Fredj Jawadi (ed.), Banks and Risk Management, special issue of Research in International Business and Finance, Elsevier, Proceedings of Second International Paris Workshop in Financial Markets and Nonlinear Dynamics, vol 39, Part B, January: 899-910.

Barnett, W. A. and G. Zhou (1994). "Financial Firms' Production and Supply-Side Monetary Aggregation Under Dynamic Uncertainty," Federal Reserve Bank of St. Louis Review 76, 133-165. Reprinted in Reprinted in W. A. Barnett and J. Binner (eds.), 2004, Functional Structure and Approximation in Econometrics, North Holland, Amsterdam, chapter 16: 381-427.

Barnett, W. A., M. J. Hinich, and W. E. Weber (1986). "The Regulatory Wedge between the Demand-Side and Supply-Side Aggregation-Theoretic Monetary Aggregates," Journal of Econometrics 33: 165185.

Barnett, W. A., M. Kirova, and M. Pasupathy (1995). "Estimating Policy-Invariant Deep Parameters in the Financial Sector, when Risk and Growth Matter," Journal of Money, Credit, and Banking 27, 14021430. Reprinted in W. A. Barnett and A. Serletis (eds.), 2000, The Theory of Monetary Aggregation, North Holland, Amsterdam, chapter 22: 530-557.

Barnett, W. A., M. Chauvet, D. Leiva-Leon, and L. Su (2016). "The Credit-Card-Services Augmented Divisia Monetary Aggregates," University of Kansas Working Paper No. 201604.

Barnett, W.A., J. Liu, R.S. Mattson, and J. van den Noort (2013). "The New CFS Divisia Monetary Aggregates: Design, Construction, and Data Sources," Open Economies Review 24: 101-124.

Belongia, M.T. and P.N. Ireland (2014). “The Barnett Critique after Three Decades: A New Keynesian Analysis.” Journal of Econometrics 183(1): 5-21.

Belongia, M. T. and P. N. Ireland (2015a), "Interest Rates and Money in the Measurement of Monetary Policy,” Journal of Business and Economic Statistics 332: 255-269.

Belongia, M. T. and P. N. Ireland (2015b), “A ‘Working’ Solution to the Question of Nominal GDP Targeting, Macroeconomic Dynamics 13(3): 508-534.

Belongia, M. T. and P. N. Ireland (2016), "Money and Output: Friedman and Schwartz Revisited," Journal of Money, Credit, and Banking 48(6): 1223-1266. 
Bernanke, Ben S (2013). “The Crisis as a Classical Financial Panic,” Fourteenth Jacques Polak Annual Research Conference, Washington, D.C., Board of Governors of the Federal Reserve System.

Brunner, Karl and Allan H. Meltzer (1967). "The Meaning of Monetary Indicators. In G. Horwich (ed.), Monetary Process and Policy, Homewood, Ill: Richard Irwin.

Brunner, Karl and Allan H. Meltzer (1990). “Money Supply,” in B. M. Friedman and F. H. Hahn (eds.), Handbook of Monetary Economics, vol 1, Elsevier, Amsterdam.

Butaru, F., Q. Chen, B. Clark, S. Das, A. Lo, and A. Siddique (2016). "Risk and Risk Management in the Credit Card Industry,” Journal of Banking and Finance 72: 218-239.

Cagan, P. (1956). Determinants and Effects of Changes in Stock of Money, 1867-1960, New York: National Bureau of Economic Research.

Cavalcanti, Ricardo de O. and Neil Wallace (1996). "Inside and Outside Money as Alternative Media of Exchange,” Journal of Money, Credit, and Banking 931(3), August: 443-457.

Chari, V. V., Lawrence J. Christiano, and Martin Eichenbaum (1995). "Inside Money, Outside Money, and Short Term Interest Rates,” Journal of Money, Credit and Banking 27(4): 1354-1386.

Cherchye, L., T. Demuynck, B. D. Rock, and P. Hjerstrand (2015). "Revealed Preference Tests for Weak Separability: An Integer Programming Approach," Journal of Econometrics 186(1): 129-141.

Crawford, Gregory, Nicola Pavanini, and Fabiano Schivardi (2015). "Asymmetric Information and Imperfect Competition in Lending Markets," CEPR Working Paper, Centre for Economic Policy Research, London, UK, April 30.

David, B., F. Abel, and W. Patrick (2016). "Debit Card and Demand for Cash," Journal of Banking and Finance 73: 55-66.

Diewert, W. (1976). “Exact and Superlative Index Numbers," Journal of Econometrics 4: 115-45. 
Fisher, Irving (1961). The Theory of Interest, New York: Macmillan.

Fixler, Dennis and Kimberly Zieschang (2016a). "FISIM Accounting," Working Paper No. WP01/2016, Centre for Efficiency and Productivity Analysis, University of Queensland.

Fixler, Dennis and Kimberly Zieschang (2016b). "Producing Liquidity," Working Paper No. WP02/2016, Centre for Efficiency and Productivity Analysis, University of Queensland.

Friedman, Milton and A. J. Schwartz (1963), A Monetary History of the United States, 1867-1960. Princeton: Princeton University Press.

Gurley, John G. and Edward S. Shaw (1960). Money in a Theory of Finance. Brookings Institution, Washington, DC.

Hancock, D. (1991). A Theory of Production for the Financial Firm, Boston: Kluwer Academic.

Hummelon, Jeffrey Rogers (2015), "The Monetary Base and Total Reserves: Fed Confusions and Misreporting," Alt-M blog sponsored by the Cato Institute, November 7.

(https://www.alt-m.org/2015/11/07/ monetary-base-total-reserves-fed-confusions-misreporting/)

Hjertstrand, Per, J. L. Swofford, and G. Whitney (2016). “Mixed Integer Programming Revealed Preference Tests of Utility Maximization and Weak Separability of Consumption, Leisure, and Money," Journal of Money, Credit, and Banking 48(7): 1547-1561.

Johnson, H. G. (1969). "Inside Money, Outside Money, Income, Wealth, and Welfare in Monetary Theory," Journal of Money, Credit and Banking, February: 30-45.

King, Robert G. and Charles I. Plosser (1987). "Nominal Surprises, Real Factors, and Propagation Mechanisms." In William A. Barnett and Kenneth Singleton (eds.), New Approaches to Monetary Economics, Cambridge University Press, Cambridge, UK: 273-292.

Magil, Michael J. P. and Martine Quinzii (2002). Theory of Incomplete Markets, Cambridge, MA: MIT Press. 
Magil, Michael J. P. and Martine Quinzii (eds.) (2008). Incomplete Markets, volumes 1 and 2, Cheltenham, UK: Edward Elgar.

Meltzer, Allan H. (1969). “Money, Intermediation, and Growth,” Journal of Economic Literature 7(1), March: 27-56.

Pesek, Boris and Thomas R. Saving (1967). Money, Wealth, and Economic Theory, New York.

Sato, K. (1975). Production Functions and Aggregation, Amsterdam: Elsevier.

Serletis, A. and P. Gogas (2014). "Divisia Monetary Aggregates, the Great Ratios, and Classical Money Demand Functions," Journal of Money, Credit and Banking 46(1): 229-41.

Shephard, R. W. (1970). Theory of Cost and Production Functions, Princeton, NJ: Princeton University Press.

Sims, C. (1969). "Theoretical Basis for a Double Deflated Index of Real Value Added," Review of Economics and Statistics 51, 470-471.

Spencer, Roger W. (1974). "Channels of Monetary Influence: A Survey," St. Louis Federal Reserve Bulletin, November: 8-26.

Stiglitz, J. and A. Weiss (1981). "Credit Rationing in Markets with Imperfect Information," American Economic Review 71(3): 393-410.

Tobin, J. (1963). "Commercial Banks as Creators of Money." In: Deane Carson (ed.), Banking and Monetary Studies, Homewood, Illinois: Richard D. Irwin. 